\title{
Targeting Thymidine Phosphorylase with Tipiracil Hydrochloride is a Safe and Effective Antithrombotic Therapy
}

Abu Hasanat Md Zulfiker, $\mathrm{PhD}^{1^{*}}$, Adam Belcher, $\mathrm{MS}^{1^{*}}$, Oliver Qiyue Li, $\mathrm{MS}^{2}$, Hong Yue, MD, $\mathrm{PhD}^{1}$, Anirban Sen Gupta, $\mathrm{PhD}^{3}$, and Li Wei, $\mathrm{MD}, \mathrm{PhD}^{1, \#}$

* These authors contribute equally to this project.

1. Department of Biomedical Sciences, Marshall University Joan C. Edwards School of Medicine, Huntington, WV, 25755, USA.

2. Marshall University Marshall Institute for Interdisciplinary Research; Huntington, WV, 25755, USA.

3. Department of Biomedical Engineering, Case Western Reserve University, Cleveland $\mathrm{OH}$ 44106, USA

Short title: Targeting TYMP as a novel antithrombotic therapy

\section{\#. Corresponding author}

Wei Li, MD, PhD

Department of Biomedical Sciences, BBSC 241G

Joan C. Edwards School of Medicine

Marshall University

One John Marshall Drive, Huntington,

West Virginia 25755-9310, USA.

Phone: 1-304-696-7342,

Fax: 1-304-696-7207

E-mail: liwe@marshall.edu

Word count: 7,515

Subject terms: Platelets, Thrombosis, and Vascular Disease 


\begin{abstract}
Rationale:

Most of the current anti-platelet drugs inhibit platelet function permanently and have systemic side effects, including thrombocytopenia and hemorrhage. We previously found that thymidine phosphorylase (TYMP), a platelet cytoplasmic protein, facilitates multiple agonist induced platelet activation and enhances thrombosis. A specific TYMP inhibitor, namely, tipiracil hydrochloride (TPI), has been approved by the U.S. Food and Drug Administration for clinical use as an auxiliary drug making it possible to be repositioned as an anti-platelet medicine.
\end{abstract}

\title{
Objective:
}

We aimed to test the hypothesis that TPI is a novel and safe anti-platelet drug by examining its role in platelet activation and thrombosis using both in vitro and in vivo studies.

\section{Methods and Results:}

By co-expression of TYMP and Lyn or Lyn-SH3 domain tagged with glutathione S-transferase, we showed the direct evidence that TYMP binds to the SH3 domain in its partners. TYMP haplodeficiency is sufficient to inhibit thrombosis in vivo regardless of gender. TPI treatment rapidly inhibited collagen- and ADP-induced platelet aggregation, which copied the phenotype of TYMP deficient platelets. Under both normal and hyperlipidemic conditions, treating wild type (WT) mice with TPI via intraperitoneal injection, intravenous injection, or gavage feeding dramatically inhibited thrombosis without inducing significant bleeding. Even administered above the effective dose, TPI has a lower bleeding side effect compared to aspirin and clopidogrel. Most importantly, intravenously delivery of TPI alone or combined with tissue plasminogen activator dramatically inhibited the growth of developing thrombi. Dual administration of very low dose of aspirin and TPI also dramatically inhibited thrombosis without disturbing hemostasis.

\section{Conclusion:}

This pharmacological study demonstrated that TYMP participates in multiple signaling pathways in platelet and plays a mechanistic role in regulating platelet activation and thrombosis. TPI, a specific TYMP inhibitor, would be a novel safe anti-platelet and anti-thrombosis medicine. 


\section{Non-standard Abbreviations and Acronyms}

GPVI glycoprotein VI

ADP adenosine diphosphate

GPCRs G G $\quad$ protein coupled receptors

TYMP thymidine phosphorylase

TPI tipiracil hydrochloride

WT wild type

$\mathrm{FeCl}_{3} \quad$ ferric chloride

PRP platelet-rich plasma

GST glutathione S-transferase

CRP collagen related peptide

tPA tissue plasminogen activator 


\section{Introduction}

Thrombotic events remain a clinically significant area for new mechanistic and therapeutic discoveries, as they are a major cause of morbidity and mortality both in the US and worldwide. ${ }^{1-3}$ However, new anti-thrombotic agents are not being developed since suitable targets are lacking. Platelet activation and hyper-aggregation at the site of vascular injury is the primary pathogenic component of thrombosis, which can lead to vessel occlusion resulting in myocardial infarction and ischemic stroke. In this context, platelet surface receptor glycoprotein VI (GPVI) confers both platelet adhesion and activation in response to exposed collagens at the site of vascular injury. ${ }^{4-6}$ The adhered and activated platelets release soluble agonists, including adenosine diphosphate (ADP), thrombin, and thromboxane $\mathrm{A}_{2}$, that activate additional platelets locally via G protein coupled receptors (GPCRs), such as ADP-receptor P2Y12 and thrombin receptor PAR1., 7 Consequently, various anti-platelet drugs, such as aspirin (COX inhibitor), clopidogrel (P2Y12 inhibitor), and vorapaxar (PAR1 inhibitor), have been developed and used clinically for the primary or secondary prevention of platelet-mediated thrombotic events. ${ }^{8-11}$ However, due to the systemic effects of their targets, these drugs have major side effects including injury to the gastrointestinal mucosa, thrombocytopenia, and systemic hemorrhage. ${ }^{2,8-}$ 11 The permanent inhibition on platelet function is also problematic for patients who need emergent surgery. ${ }^{12}$ In addition, some patients do not respond to the current anti-platelet regimens and still have a high incidence of vascular thrombosis. ${ }^{2}$ Therefore, there are significant clinical interests in elucidating unique molecular mechanisms of platelet-mediated thrombus formation, which can lead to the development of a novel anti-platelet therapy with minimized systemic risks. ${ }^{2,13}$ Currently, all anti-platelet drugs target platelet surface receptors and drugs that safely inhibit platelet function by targeting intracellular proteins have not been developed.

Human thymidine phosphorylase (TYMP) was first isolated from amniochorion ${ }^{14}$ and later from human platelets, ${ }^{15}$ thus it is also known as platelet-derived endothelial cell growth factor. ${ }^{16}$ TYMP is mainly found inside the cell due to the lack of an amino-terminal hydrophobic leader sequence required for cell secretion. ${ }^{15}$ TYMP belongs to the family of pyrimidine nucleoside phosphorylase, and its primary function is to drive the salvage pathway of pyrimidine nucleosides. ${ }^{17-19}$ In the presence of inorganic phosphate, TYMP reversely catalyzes thymidine to thymine and 2-D-deoxyribose-1-phosphate, and the latter is further degraded to 2-Ddeoxyribose. ${ }^{19,20}$ TYMP also has deoxyribosyl transferase activity through transferring the deoxyribosyl moiety from a pyrimidine nucleoside to another pyrimidine base, resulting in the formation of a new pyrimidine nucleoside. ${ }^{19,21}$ Functional TYMP acts as a homodimer and plays a key role in the pyrimidine nucleoside metabolism, ensuring a sufficient pyrimidine nucleotides pool for DNA repair and replication. However, the role of TYMP in platelets, a non-nucleated cell, remains unclear. Our recent study demonstrated that TYMP is a potential signaling protein and it may transfer cell signaling through the binding of its proline-rich N-terminus to the SH3 domain in its partner proteins. ${ }^{19,22}$ TYMP deficiency dramatically inhibited platelet response to the conventional agonists, such as collagen, ADP, and thrombin. ${ }^{22}$ Inhibition of TYMP activity with a novel TYMP inhibitor, KIN59, ${ }^{23}$ dramatically inhibited platelet activation in vitro and thrombosis in vivo. ${ }^{22}$ These data suggest that TYMP is a targetable intracellular protein in platelets and its inhibition is antithrombotic. The potent and specific TYMP inhibitor, tipiracil hydrochloride (TPI), is an auxiliary component of a novel anticancer drug, Lonsurf. Lonsurf was recently approved by the FDA for clinical use, suggesting that TPI could be repositioned as a novel antiplatelet and anti-thrombotic drug. In this study, we examined the role of TPI on 
platelet activation and thrombosis using in vitro and in vivo studies and have provided evidence that TPI-mediated TYMP inhibition is a safe and effective antithrombotic therapy. TPI is suitable as both a primary and secondary prevention for patients with high risk of thrombotic cardiovascular diseases, and combination of low dose TPI and aspirin could be a new dual antiplatelet regimen.

\section{Methods}

The authors declare that all supporting data are available within the article and its online supplementary files.

\section{Experiment animals}

Tymp $^{-/-}$mouse strain was generated by Dr. Hirano’s laboratory as mentioned before. ${ }^{22,24}$ Wild type C57BL/6 mice (WT) were purchased from Jackson Laboratory (Bar Harbor, ME). All procedures and manipulations of animals have been approved by the Institutional Animal Care and Use Committee of Marshall University (IACUC\#: 1033528).

\section{Murine carotid artery thrombosis model and tail bleeding assay}

Detailed ferric chloride $\left(\mathrm{FeCl}_{3}\right)$ induced carotid artery thrombosis model has been described before. ${ }^{25}{ }^{26}$ Vessel injury was induced by $7.5 \% \mathrm{FeCl}_{3}$ solution to the carotid artery for 1 minute. Thrombi formation was observed in real-time using an intravital microscope. The endpoints were set as follows: 1) blood flow has ceased for $>30$ seconds; or 2) occlusion is not seen after 30 minutes of $\mathrm{FeCl}_{3}$ injury. In this case, 30 minutes was assigned to that mouse for the statistical analysis. In some experiments, a jugular vein catheter prepared with P-10 tubing was placed for drug administration after 5 minutes of thrombus initiation. Thrombus formation was continually monitored using the endpoints mentioned above. Tail bleeding assay was either conducted on mice immediately after the thrombosis study or on mice that were not used for the in vivo thrombosis study. ${ }^{27}$

\section{Mouse platelet aggregation assay}

Mice were anesthetized with ketamine/xylazine (100/10 mg/kg) and whole blood were drawn through inferior vena cava puncture using $0.109 \mathrm{M}$ sodium citrate as an anticoagulant. ${ }^{22}$, 28, 29 Platelet-rich plasma (PRP) was used for platelet aggregation assay. In some experiments, platelets were pretreated with different concentrations of TPI for 2 min (or indicated times) before adding $\mathrm{CaCl}_{2} / \mathrm{MgCl}_{2}$ at a final concentration of $1 \mathrm{mM}$ and agonists as indicated in the Results. Same volume of vehicle (DMSO or saline)-treated platelets was used as controls.

\section{Cellix flow chamber-based platelet adhesion and aggregation assay}

Cellix flow chambers were coated with collagen $10 \mu \mathrm{g} / \mathrm{mL}$ in PBS. Whole blood was drawn from mouse inferior vena cava using $0.109 \mathrm{M}$ sodium citrate as an anticoagulant, stained with Rhodamine 6G, and then used for the flow chamber mediated adhesion and aggregation assay. Some of the whole blood was treated with or without TPI before it was perfused into the chamber.

\section{Compare the therapeutic effect of TPI to aspirin and clopidogrel}


8 to 10 week-old male WT mice were gavage fed with either TPI, aspirin, or clopidogrel once daily for one week, then subsequently used in an in vivo thrombosis study. Tail bleeding assay was conducted on these mice immediately after the thrombosis study.

\section{Examine the effect of TYMP inhibition on thrombosis under hyperlipidemia}

WT mice were fed a western diet (WD, TD.88137) for a total of 4 weeks. For a separate group of mice, the diet was changed to a customized diet (TD.190501), which has the same component as TD.88137 with the addition of $10.7 \mathrm{mg} / \mathrm{kg}$ TPI, for the last 7 days of feeding. Mice fed with TD.190501 received approximately $1 \mathrm{mg} / \mathrm{kg} /$ day of TPI. These mice were then subjected to the thrombosis study using the $7.5 \% \mathrm{FeCl}_{3}$ induced thrombosis model.

\section{Evaluation of platelet signaling activation}

Platelets in PRP were stimulated with $2.5 \mu \mathrm{M}$ ADP for $0,1,3$, and 5 minutes, then lysed with radioimmunoprecipitation assay buffer containing proteinase/phosphatase inhibitor cocktail. The lysates were subsequently used for AKT activation immunoblotting assays. ADP-stimulated p-selectin expression was analyzed by flowcytometry.

\section{Generation of fusion proteins to determine that TYMP binds to LYN through the SH3 binding domain.}

Human SH3 domain nucleotides (hLynSH3, amino acids 63-123) were amplified by PCR and cloned into a mammalian expression vector pEBG (Addgene, plasmid \# 22227) with an Nterminal glutathione S-transferase (GST) affinity tag (pEBG-GST-hLynSH3). We had previously constructed a pCDNA6B/his-hTYMP plasmid vector. ${ }^{30}$ pEBG-GST-hLynSH3 and pCDNA6B/his-hTYMP plasmids were co-transfected into COS-7 cells, lysed in a Pierce ${ }^{\mathrm{TM}}$ IP Lysis Buffer (ThermoFisher Scientific), and used for GST pull down assay. Eluates were used for western blot assay to confirm the presence of TYMP.

pEGFP-N1-human Lyn-GFP and pCDNA6B/his-hTYMP plasmids were also cotransfected into the COS-7 cells. TYMP was pulled down using immobilized Ni-NTA on magnetic sepharose beads (GE Healthcare Life Sciences) for His-tagged protein purification. His-hTYMP eluates were used for western blot assay for Lyn.

Statistics. Data are expressed as mean \pm SEM. Results were analyzed by 2-tailed Student's $t$ test or 1-way ANOVA with Bonferroni post-hoc test for multiple comparisons using GraphPad Prism (version 8.3.1). $P<0.05$ was considered statistically significant.

\section{Supplementary methods}

For detailed experimental designs, sample preparation, and experimental conditions, please find the Supplementary Methods provided online.

\section{Results}

\section{TYMP binds to Lyn SH3 domain}

Our previous study demonstrated that TYMP is a novel signaling protein and it binds to the SH3 domain-containing proteins, probably through its proline rich $\mathrm{N}$-terminus. ${ }^{22}$ This finding was confirmed by overexpressing full length human TYMP and Lyn in Cos-7 cells. By pulling 
down His-Tagged TYMP using the lysates prepared from the co-transfected cells, we found both endogenous and overexpressed Lyn present in the elute (Fig. 1A), which corroborates our previous finding using human and mouse platelet lysates. To show the direct evidence, we further generated a GST-SH3 fusion protein and examined its binding to human TYMP by GST pull-down assay. As shown in Fig. 1B, pulling down GST-SH3 also pulled down human TYMP. These data showed the direct evidence that TYMP binds to its partner proteins through the SH3 domain.

\section{TYMP-deficiency attenuates platelet aggregation to collagen-coated surfaces}

Adhesion to the injury site is an essential function for platelets and is generally viewed as the first step of aggregation, during which specific membrane receptors on the platelet surface binds to cellular and constituents of the extracellular matrix and the vessel wall. ${ }^{31}$ The initial functional receptors primarily include platelet GPIb-XI-V and GPVI. In our previous study, we have found that TYMP deficiency likely does not affect the initial platelet adhesion in the in vivo thrombosis model. ${ }^{22}$ To examine this finding, we coated Cellix Vena8 Fluoro+ chamber with type I collagen, ${ }^{32,33}$ and perfused the chambers with fluorescently labeled mouse whole blood. As shown in Fig. 2A, we found that TYMP-deficiency did not affect platelet binding to the type I collagen-coated surface. However, TYMP-deficiency dramatically decreased platelet aggregation at the end of the three-minute observation. Inhibition of TYMP with $50 \mu \mathrm{M}$ TPI also significantly reduced platelet aggregation to the collagen-coated surface (Fig. 2B). These data suggest that TYMP plays a functional role in GPVI signaling-mediated platelet activation and aggregation; however, TYMP deficiency or inhibition does not affect platelet adhesion to collagen.

\section{Tipiracil hydrochloride, a potent and specific TYMP inhibitor, attenuates platelet activation}

We have shown that TYMP deficiency significantly attenuated platelet aggregation and P-selectin expression in response to collagen, collagen related peptide (CRP), ADP and thrombin. ${ }^{22}$ TPI, a FDA-approved TYMP inhibitor, recently became commercially available. Therefore, we examined its effects on inhibiting platelet activation and preventing thrombosis. TPI dose-dependently (250, 125, and $62.5 \mu \mathrm{M}$ ) inhibited $0.5 \mu \mathrm{g} / \mathrm{ml}$ CRP-induced platelet shape change (not shown) and $50 \mu \mathrm{M}$ completely blocked CRP-induced platelet aggregation (Fig. 3A). In line with the findings in Fig.2B, pretreatment of platelets with TPI also dose-dependently inhibited collagen-induced platelet aggregation (Fig. 3B and C), which phenocopied the behavior of TYMP-deficient platelets. TPI also attenuated ADP-induced WT platelet aggregation but had no effect on Tymp ${ }^{-/-}$platelets (Fig. 3D), suggesting that the inhibitory effects of TPI on platelet activation are mediated by TYMP inhibition. This hypothesis is further supported by examination of ADP induced AKT phosphorylation, which has been used as a marker of platelet activation in many studies. ${ }^{22,}{ }^{34}$ As shown in Fig. 3E, we found that ADP-induced phosphorylation of AKT at S473 was bi-phasic. TYMP deficiency likely had no effect on AKT activation within the first minutes after ADP stimulation, but it dramatically delayed the second phase of AKT phosphorylation. In the second phase of AKT phosphorylation, Tymp ${ }^{-/-}$platelets took 10 minutes to reach the AKT phosphorylation levels seen in WT platelets after 5 minutes. Inhibition of TYMP with TPI also dramatically reduced ADP-stimulated AKT phosphorylation, 
especially the second phase (Fig. 3F), and attenuated ADP-stimulated p-selectin expression (Fig. 3G).

\section{Tymp deficiency results in significant anti-thrombotic effects}

We previously reported that TYMP haploinsufficiency or complete deletion significantly inhibited thrombosis in male mice. ${ }^{22}$ We have now found that TYMP deficiency in female mice also significantly inhibits thrombosis (Fig. 4A and B). When combining both male and female mice together, we found that cessation of blood flow within 30 minutes was seen in all WT mice $(n=17)$ with an average vessel occlusion time of $9.81 \pm 2.25 \mathrm{~min}$ (Fig. 4C and D). 10 of the 18 Tymp $^{+/-}$mice and 7 of the 16 Tymp $^{-/-}$mice showed flow cessation within the 30 min observation period, with average occlusion times $>20 \mathrm{~min}$. These data suggest that TYMP, a platelet cytosolic protein, plays a mechanistic role in platelet activation and thrombosis, which is independent of gender. Partial deficiency of TYMP is enough to achieve a significant antithrombotic effect.

\section{TPI inhibits thrombosis under both normal and hyperlipidemia conditions without disturbing hemostasis}

Having shown that inhibition of TYMP with TPI significantly inhibits CRP-, collagen-, and ADP-induced platelet aggregation in vitro, we further examined the effects of TPI on in vivo thrombosis. Intraperitoneal injection of TPI once per day for three days at a dose of $17 \mathrm{mg} / \mathrm{kg}$, which, assuming that total body water is $60 \%$ of body weight, equals $100 \mu \mathrm{M}$ plasma concentration, completely inhibited occlusive thrombus formation in the carotid arteries induced by $7.5 \% \mathrm{FeCl}_{3}$ (Fig. 5A). Importantly, this treatment did not significantly affect tail-bleeding time (Fig. 5B). Direct intravenous injection of TPI at doses of 1.7 and $0.17 \mathrm{mg} / \mathrm{kg}$, which equals to 10 and $1 \mu \mathrm{M}$ plasma concentration based on the calculation mentioned above, also significantly inhibited thrombosis (Fig. 5C) when compared with mice receiving saline injection alone. Interestingly, gavage feeding of TPI at a lower dose of $60 \mu \mathrm{g} / \mathrm{kg} / \mathrm{day}$, which equals a plasma concentration of $340 \mathrm{nM}$ that is 10 -fold higher than the TPI IC50 of $34 \mathrm{nM}$, for 3 days also significantly inhibited in vivo thrombosis (Fig. 5D \& E). These data strongly suggest that inhibition of TYMP with its specific inhibitor is an effective antithrombotic therapy.

Most of the patients with atherothrombotic vascular diseases have comorbid hyperlipidemia and the associated mortality rates are still unacceptably high. We previously reported that hyperlipidemia leads to platelet hyperactivity, which may contribute to the development of the pro-thrombotic state. ${ }^{35}$ We found that WT mice fed with a WD for 4 weeks is sufficient enough to shorten the thrombosis time when compared to age-matched mice fed with chow. TPI (1 mg/kg) treatment for one week dramatically reduced hyperlipidemia-enhanced thrombosis (Fig. 5F, G, and $\mathrm{H}$ as well online supplementary video I-III).

\section{Compare the side effects of TPI vs. aspirin and clopidogrel}

Current anti-platelet and anti-thrombotic drugs require chronic dosing to be effective and have bleeding side effects. ${ }^{2,13,36}$ Aspirin and clopidogrel are the most frequently used antithrombotic drugs clinically. We thus compared their therapeutic and side effects with TPI. We gavage fed WT mice with different doses of aspirin and clopidogrel for one week, and then subjected them to the $7.5 \% \mathrm{FeCl}_{3}$-induced thrombosis model. We found that $1 \mathrm{mg} / \mathrm{kg} /$ day aspirin 
and $2.5 \mathrm{mg} / \mathrm{kg} /$ day clopidogrel were the lowest effective doses that achieved a significant antithrombotic effect when compared with WT mice without any treatment (Fig. 6A and supplementary video IV and V). Although we have found that gavage feeding of TPI, as low as $60 \mu \mathrm{g} / \mathrm{kg} /$ day, significantly inhibited thrombosis in vivo (Fig. 5D \& E), we chose a higher dose of TPI, $1 \mathrm{mg} / \mathrm{kg} /$ day, in order to explore the potential side effects. We then compared the results to aspirin- and clopidogrel-treated WT mice (Fig. 6B and supplementary video IV-VI). When comparing the tail bleeding time, although there were no differences found among the three groups, clopidogrel-treated mice had the longest bleeding time (470 \pm 70 seconds), the aspirintreated mice were second (336 \pm 93 seconds), and the TPI-treated mice had the shortest bleeding time (302 \pm 67 seconds) (Fig. 6C). 75\% (3 of the 4) in the clopidogrel group, 50\% (3 of the 6) in the aspirin group, and $28.5 \%$ (2 of the 7 ) in the TPI group were considered to have bleeding side effects (Fig. 6D). Mice treated with $1 \mathrm{mg} / \mathrm{kg} / \mathrm{day}$ of TPI had significantly decreased frequency of bleeding than the clopidogrel-treated mice $(\mathrm{p}=0.034)$.

\section{TPI is a quick-acting anti-thrombotic drug and co-administration with tissue plasminogen activator (tPA) reduces the tPA dose needed for effective thrombolysis without disturbing hemostasis.}

The window for treating patients with acute myocardial infarction or ischemic stroke is narrow and tPA is the only FDA-approved clot-busting drug. Intravenous perfusion of tPA has a high risk of systemic coagulopathies and bleeding complications ${ }^{37}$. By using the $\mathrm{FeCl}_{3}$-induced carotid artery thrombosis model, we have found that bolus injection of tPA (Activase, $1 \mathrm{mg} / \mathrm{kg}$ ) 5 min after initiation of vascular injury effectively lysed the established thrombi. ${ }^{26}$ However, due to de novo platelet activation, we also observed persistent formation of new platelet-rich thrombi after tPA administration; thus, thrombi underwent repeated size variations. ${ }^{26}$ By bolus injection of 17 and $1 \mathrm{mg} / \mathrm{kg}$ TPI to mice $5 \mathrm{~min}$ after $7.5 \% \mathrm{FeCl}_{3}$-induced vessel injury, we found that thrombosis formation was significantly prolonged or there was no blood flow cessation in those WT mice (Fig. 7A). These data suggest that TPI may be a quick-acting anti-thrombotic drug. We further tested the minimal effective dose of TPI on inhibiting the growth of the on-site thrombus and found that the lowest effective dose is between $50-100 \mu \mathrm{g} / \mathrm{kg}$. By using the same thrombosis model, we also found that the lowest effective dose of tPA on thrombolysis is between 0.25 to $0.5 \mathrm{mg} / \mathrm{kg}$. Lowering the doses of tPA to 0.25 and $0.125 \mathrm{mg} / \mathrm{kg}$ had no thrombolytic action (Fig. 7B). Interestingly, when we co-administered TPI $75 \mu \mathrm{g} / \mathrm{kg}$ and tPA $0.25 \mathrm{mg} / \mathrm{kg}$, as shown in Fig. 7C and 7D, as well as supplementary video VII, we found a significant inhibition of the growth of the on-site thrombi compared to each drug was used individually. Increasing doses of either TPI or tPA in combination also significantly prolonged the thrombosis time (Fig. 7C). Most importantly, high doses of TPI (1-4 mg/kg) only slightly prolonged tail-bleeding time to $3.74 \pm 0.73 \mathrm{~min}$. These data suggest that co-administration of tPA and TPI reduces the tPA dose required for thrombolysis. TYMP inhibition alone or in combination with a low dose of tPA could be a novel strategy for treating patients with acute myocardial infarction or ischemic stroke without causing coagulopathy.

\section{Combination of TPI and aspirin is a potential new, safe dual antiplatelet therapy.}

Dual anti-platelet therapy is commonly used in the first several months after cardiac procedures such as stent placement and transcatheter aortic valve implantation. ${ }^{38,39}$ Combination of aspirin and P2Y12 inhibitor greatly increases the risk of bleeding, so there is still a need for a 
robust acute anti-thrombotic treatment with lesser bleeding risk. ${ }^{40}$ We thus examined if combination of aspirin and TPI could be a new dual anti-platelet therapy with neglectable side effect. We chose aspirin $0.5 \mathrm{mg} / \mathrm{kg}$ and TPI $50 \mu \mathrm{g} / \mathrm{kg}$, as treating WT mice with these two drugs alone in the selected dose had no effect on thrombosis (Fig. 6A and 7A). As shown in Fig. 8A \& $\mathbf{B}$, gavage feeding of WT mice with this regimen significantly prolonged time to occlusive thrombus formation when compared with $0.5 \mathrm{mg} / \mathrm{kg}$ aspirin alone. When compared the tail bleeding time with WT mice that were not received any treatment, we found that combination of low doses of aspirin and TPI does not cause bleeding (Fig. 8C).

\section{Discussion}

Vascular thrombosis is the primary event in life threatening diseases, such as myocardial infarction or ischemic stroke, and platelet activation and aggregation are major components of thrombosis. Consequently, various anti-platelet medications are used clinically for the primary or secondary prevention of thrombosis. However, most of these drugs irreversibly block platelet surface receptors involved in platelet activation and aggregation, which results in systemic side effects, including thrombocytopenia and hemorrhage. Therefore, there is a urgent need to elucidate unique molecular mechanisms of platelet-mediated arterial thrombus formation that can be modulated to allow targeted anti-platelet therapy while minimizing systemic risks ${ }^{2,13}$. In addition, to our best knowledge, no antiplatelet drugs have been developed to target platelet cytosolic proteins. We recently discovered that TYMP, a platelet cytoplasmic protein, plays important roles in maintaining normal platelet function, and TYMP is also essential for platelet activation induced by multiple agonists, including collagen, ADP, and thrombin. ${ }^{22}$ We have now found that TYMP-enhanced platelet activation is independent of sex and that TYMP deficiency in female mice achieved a similar anti-thrombotic effect to what we saw in male mice. ${ }^{22}$ These new data suggest a universal and mechanistic role of TYMP on platelet activation and thrombosis.

In this study, we thoroughly examined whether TYMP could be inhibited in vivo as well as the consequences following TYMP inhibition using its specific and potent inhibitor, TPI. TPI is water soluble $(>13.25 \mathrm{mg} / \mathrm{ml})$. These is no published study examined the pharmacokinetics of TPI alone. Administration of a single dose of Lonsurf at $35 \mathrm{mg} / \mathrm{m}^{2}$ generates the absorption rate of TPI of area under curve is $301 \mathrm{ng} \cdot \mathrm{h} / \mathrm{ml}$. The maximum plasma concentration of TPI is 69 $\mathrm{ng} / \mathrm{ml}$, which was observed at $3 \mathrm{~h}$ after administration. ${ }^{41}$ At steady state, TPI half-life is $2.4 \mathrm{~h}$, and around $77 \%$ is excreted through faeces and urinary with unchanged structure. ${ }^{42}$ TPI was delivered to mice using three different routes, including intraperitoneal injection, intravenous injection, and oral administration, and the effect was tested using different disease models. Our data clearly demonstrated that TPI is an effective and safe anti-thrombotic compound, even under a hyperlipidemic condition. The effective dose of TPI could be as low as $60 \mu \mathrm{g} / \mathrm{kg} / \mathrm{day}$ without significantly affecting hemostasis. Most importantly, intravenous injections of TPI, either delivered alone or in combination with tPA, also significantly inhibited the growth of the ongoing thrombi, which makes TYMP inhibition a potential alternative remedy for patients with acute myocardial infarction or stroke. This fast-acting characteristic also indicates that TPI can be used for percutaneous coronary intervention and transcatheter aortic valve implantation etc, either alone or combined with other drugs to temporally inhibit platelet function, as TYMP inhibitors rapidly and reversibly inhibit platelet aggregation. ${ }^{22}$ 
TYMP has a pro-angiogenic effect and previous studies of TYMP are primarily focused on its function on endothelial cells ${ }^{16,43-45}$ and cancer angiogenesis. ${ }^{46-48}$ Platelets are a major source of TYMP, with each human platelet containing about 5,400 to 11,600 copies of TYMP, ${ }^{49}$, ${ }^{50}$ but the function of TYMP in platelet physiology and function remains unclear. TYMP has been implicated in diseases that have high risk of thrombosis, such as atherosclerosis, ${ }^{51,52}$ cancer, ${ }^{53,54}$ and diabetes mellitus. ${ }^{55}$ In addition, ionizing radiation, which induces significant TYMP expression, has been associated with thrombotic vascular occlusion. ${ }^{56}$ In the current study, we found that TYMP deficiency or inhibition does not affect platelet binding to the collagen-coated surface; however, it dramatically attenuated platelet aggregation on the collagencoated surface in a flow chamber assay. In combination with our published data, ${ }^{22}$ these data further demonstrated that TYMP likely plays a more important role in the GPVI signaling pathway. GPVI is found exclusively on platelets and megakaryocytes and is the predominant platelet receptor for collagen. ${ }^{57}$ Deficiency of GPVI in humans and in mice is not associated with a strong bleeding diathesis. ${ }^{58}$ Hitherto, there is no effective and convenient inhibitor targets GPVI. A recent phase I study using Revacept, a dimeric GPVI-Fc fusion protein that blocks collagen/GPVI binding mediated platelet activation, demonstrated that targeting the GPVI signaling is a safe intervention. ${ }^{59}$ However, Revacept is delivered by intravenous injection, therefore has limited situational use, such as percutaneous coronary intervention. ${ }^{60}$ Revacept has no effects on circulating resting platelets, which indicates that it may have no effect on hyperactive platelets under certain diseased conditions. In contrast, our data suggest that TPI may have more broad indications than the other anti-platelet drugs.

In addition to GPVI signaling, TYMP also participates in GPCR-mediated platelet activation. In our previous study, we showed that TYMP deficiency reduced ADP-induced platelet p-selectin expression. Here, we further demonstrated that TYMP deficiency or inhibition attenuated ADP-induced AKT phosphorylation in platelets. ADP-induced platelet activation requires concomitant signaling from both P2Y1 and P2Y12 receptors that couple to $G_{\alpha q}$ and $G_{\alpha i}$, respectively. However, ADP-induced AKT activation is predominantly mediated by the platelet P2Y12 receptor. ${ }^{61}$ While we still do not know how TYMP affects GPCR signaling pathways, TYMP deficiency may put a "brake” on autocrine or paracrine mechanisms of platelet GPCR activation.

These data provide a strong rationale that TPI could be repositioned as a potential antithrombotic medicine. To this end, we compared the prophylactic therapeutic effects and side effects of TPI with aspirin and clopidogrel using the murine $\mathrm{FeCl}_{3}$ induced thrombosis model. We found that the lowest dose for aspirin and clopidogrel in inhibiting mouse thrombosis is 1 $\mathrm{mg} / \mathrm{kg}$ and $2.5 \mathrm{mg} / \mathrm{kg}$, respectively. As predicted, these doses of aspirin and clopidogrel dramatically prolonged bleeding time. Although a high dose of TPI (1mg/kg) occasionally prolonged bleeding time in some mice, mice that received doses of TPI (60 $\mu \mathrm{g} / \mathrm{kg})$ showed no prolonged bleeding time in all cases (Supplementary Figure I). As an auxiliary component of the anti-cancer drug, Lonsurf (TAS-102), TPI has been evaluated in clinical trials ${ }^{62-65}$ and has been shown to be systemically safe. Neither systemic bleeding nor mitochondrial neurogastrointestinal encephalomyopathy, an extremely rare autosomal recessive disease that is reportedly associated with TYMP gene loss-of-function mutations, was observed. TYMP deficiency does not affect high dose thrombin-stimulated platelet activation. ${ }^{22}$ These data suggest that TPI may be safer and more beneficial than the current anti-platelet drugs. Most importantly, oral administration of very low doses of aspirin and TPI dramatically inhibited thrombosis without inducing any coagulopathy, suggesting that this combination could be a novel remedy 
for patients with high risk of thrombosis. Clinical trial studies are necessary to demonstrate this hypothesis.

In summary, our study demonstrated that TYMP, a platelet cytosolic protein, plays an important role in platelet activation and thrombosis. TYMP can be safely and rapidly inhibited by TPI. TPI-mediated TYMP inhibition dramatically inhibited platelet activation and thrombosis in both normal and hyperlipidemic conditions, as well as in different disease models. Under effective anti-thrombotic doses, TPI does not cause bleeding disorders, as found in patients treated with other anti-platelet drugs. 
bioRxiv preprint doi: https://doi.org/10.1101/2020.04.25.061234; this version posted April 27, 2020. The copyright holder for this preprint (which was not certified by peer review) is the author/funder. All rights reserved. No reuse allowed without permission.

\section{Acknowledgements}

No other persons besides the authors have made substantial contributions to this manuscript. 


\section{Sources of Funding}

This study is supported by Marshall University Institute Fund (To Dr. Wei Li), Marshall University, School of Medicine and College of Pharmacy Collaborative Grant (PI: Dr. Wei Li), NIH R15HL145573 (PI: Wei Li), NIH R01HL129179 (PI: Anirban Sen Gupta, Co-I: Wei Li), NIH R01HL130090 (PI: Thomas M McIntyre, Co-I Wei Li) and WV-INBRE grant P20GM103434 (PI: Gary Rankin). 
bioRxiv preprint doi: https://doi.org/10.1101/2020.04.25.061234; this version posted April 27, 2020. The copyright holder for this preprint (which was not certified by peer review) is the author/funder. All rights reserved. No reuse allowed without permission.

\section{Disclosures}

None 


\section{List of supplemental materials}

\section{Expanded Materials \& Methods}

Online Video 1 - VII

Online Figure I

Legend for supplemental figure and videos. 


\section{References}

1. Day ISCfWT. Thrombosis: A major contributor to the global disease burden. $J$ Thromb Haemost. 2014;12:1580-1590

2. Jackson SP. Arterial thrombosis--insidious, unpredictable and deadly. Nat Med. 2011;17:1423-1436

3. Murray CJ, Vos T, Lozano R, et al. Disability-adjusted life years (dalys) for 291 diseases and injuries in 21 regions, 1990-2010: A systematic analysis for the global burden of disease study 2010. Lancet. 2012;380:2197-2223

4. Ezumi Y, Shindoh K, Tsuji M, Takayama H. Physical and functional association of the src family kinases fyn and lyn with the collagen receptor glycoprotein vi-fc receptor gamma chain complex on human platelets. The Journal of experimental medicine. 1998;188:267276

5. Furie BC, Furie B. Tissue factor pathway vs. Collagen pathway for in vivo platelet activation. Blood Cells Mol Dis. 2006;36:135-138

6. Stegner D, Nieswandt B. Platelet receptor signaling in thrombus formation. $J$ Mol Med (Berl). 2011;89:109-121

7. Smyth SS, Woulfe DS, Weitz JI, et al. G-protein-coupled receptors as signaling targets for antiplatelet therapy. Arteriosclerosis, thrombosis, and vascular biology. 2009;29:449-457

8. Depta JP, Bhatt DL. New approaches to inhibiting platelets and coagulation. Annu Rev Pharmacol Toxicol. 2015;55:373-397

9. Franchi F, Angiolillo DJ. Novel antiplatelet agents in acute coronary syndrome. Nat Rev Cardiol. 2015;12:30-47

10. Desai NR, Bhatt DL. The state of periprocedural antiplatelet therapy after recent trials. JACC Cardiovasc Interv. 2010;3:571-583

11. de Souza Brito F, Tricoci P. Novel anti-platelet agents: Focus on thrombin receptor antagonists. J Cardiovasc Transl Res. 2013;6:415-424

12. Chassot PG, Delabays A, Spahn DR. Perioperative antiplatelet therapy: The case for continuing therapy in patients at risk of myocardial infarction. Br J Anaesth. 2007;99:316328

13. Capodanno D, Ferreiro JL, Angiolillo DJ. Antiplatelet therapy: New pharmacological agents and changing paradigms. J Thromb Haemost. 2013;11 Suppl 1:316-329

14. Kubilus J, Lee LD, Baden HP. Purification of thymidine phosphorylase from human amniochorion. Biochimica et biophysica acta. 1978;527:221-228

15. Desgranges C, Razaka G, Rabaud M, Bricaud H. Catabolism of thymidine in human blood platelets: Purification and properties of thymidine phosphorylase. Biochimica et biophysica acta. 1981;654:211-218

16. Miyazono K, Okabe T, Urabe A, Takaku F, Heldin CH. Purification and properties of an endothelial cell growth factor from human platelets. The Journal of biological chemistry. 1987;262:4098-4103

17. Bronckaers A, Aguado L, Negri A, Camarasa MJ, Balzarini J, Perez-Perez MJ, Gago F, Liekens S. Identification of aspartic acid-203 in human thymidine phosphorylase as an important residue for both catalysis and non-competitive inhibition by the small molecule "crystallization chaperone" 5'-o-tritylinosine (kin59). Biochemical pharmacology. 2009;78:231-240 
18. Liekens S, Bronckaers A, Perez-Perez MJ, Balzarini J. Targeting platelet-derived endothelial cell growth factor/thymidine phosphorylase for cancer therapy. Biochemical pharmacology. 2007;74:1555-1567

19. Li W, Yue H. Thymidine phosphorylase: A potential new target for treating cardiovascular disease. Trends Cardiovasc Med. 2018;28:157-171

20. Norman RA, Barry ST, Bate M, et al. Crystal structure of human thymidine phosphorylase in complex with a small molecule inhibitor. Structure. 2004;12:75-84

21. Schwartz M. Thymidine phosphorylase from escherichia coli. Properties and kinetics. European journal of biochemistry / FEBS. 1971;21:191-198

22. Li W, Gigante A, Perez-Perez MJ, Yue H, Hirano M, McIntyre TM, Silverstein RL. Thymidine phosphorylase participates in platelet signaling and promotes thrombosis. Circulation research. 2014;115:997-1006

23. Liekens S, Balzarini J, Hernandez AI, De Clercq E, Priego EM, Camarasa MJ, Perez-Perez MJ. Thymidine phosphorylase is noncompetitively inhibited by 5'-o-trityl-inosine (kin59) and related compounds. Nucleosides, nucleotides \& nucleic acids. 2006;25:975-980

24. Lopez LC, Akman HO, Garcia-Cazorla A, et al. Unbalanced deoxynucleotide pools cause mitochondrial DNA instability in thymidine phosphorylase-deficient mice. Human molecular genetics. 2009;18:714-722

25. Li W, McIntyre TM, Silverstein RL. Ferric chloride-induced murine carotid arterial injury: A model of redox pathology. Redox Biol. 2013;1:50-55

26. Li W, Nieman, M., Sen Gupta, A. Ferric chloride-induced murine thrombosis models. $J$. Vis. Exp. 2016;115:e54479

27. Pawlowski CL, Li W, Sun M, Ravichandran K, Hickman D, Kos C, Kaur G, Sen Gupta A. Platelet microparticle-inspired clot-responsive nanomedicine for targeted fibrinolysis. Biomaterials. 2017;128:94-108

28. Chen K, Li W, Major J, Rahaman SO, Febbraio M, Silverstein RL. Vav guanine nucleotide exchange factors link hyperlipidemia and a prothrombotic state. Blood. 2011;117:57445750

29. Ghosh A, Li W, Febbraio M, Espinola RG, McCrae KR, Cockrell E, Silverstein RL. Platelet cd36 mediates interactions with endothelial cell-derived microparticles and contributes to thrombosis in mice. The Journal of clinical investigation. 2008;118:19341943

30. Yue H, Tanaka K, Furukawa T, Karnik SS, Li W. Thymidine phosphorylase inhibits vascular smooth muscle cell proliferation via upregulation of stat3. Biochimica et biophysica acta. 2012;1823:1316-1323

31. Ruggeri ZM, Mendolicchio GL. Adhesion mechanisms in platelet function. Circulation research. 2007;100:1673-1685

32. Gupta N, Li W, Willard B, Silverstein RL, McIntyre TM. Proteasome proteolysis supports stimulated platelet function and thrombosis. Arteriosclerosis, thrombosis, and vascular biology. 2014;34:160-168

33. Srikanthan S, Li W, Silverstein RL, McIntyre TM. Exosome poly-ubiquitin inhibits platelet activation, downregulates cd36 and inhibits pro-atherothombotic cellular functions. $J$ Thromb Haemost. 2014;12:1906-1917

34. Woulfe DS. Akt signaling in platelets and thrombosis. Expert Rev Hematol. 2010;3:81-91 
35. Chen K, Febbraio M, Li W, Silverstein RL. A specific cd36-dependent signaling pathway is required for platelet activation by oxidized low-density lipoprotein. Circulation research. 2008;102:1512-1519

36. Surin WR, Prakash P, Barthwal MK, Dikshit M. Optimization of ferric chloride induced thrombosis model in rats: Effect of anti-platelet and anti-coagulant drugs. J Pharmacol Toxicol Methods. 2010;61:287-291

37. Adams HP, Jr., Adams RJ, Brott T, et al. Guidelines for the early management of patients with ischemic stroke: A scientific statement from the stroke council of the american stroke association. Stroke. 2003;34:1056-1083

38. Ando T, Takagi H, Briasoulis A, Afonso L. Single versus dual anti-platelet therapy post transcatheter aortic valve implantation: A meta-analysis of randomized controlled trials. $J$ Thromb Thrombolysis. 2017;44:448-456

39. Pirlet C, Legrand V, Nyssen A, Pierard L, Gach O. Duration of dual anti-platelet therapy state of the art after the dapt and pegasus-timi 54 trials. Acta Cardiol. 2017;72:256-264

40. Alexander JH, Wojdyla D, Vora AN, et al. The risk / benefit tradeoff of antithrombotic therapy in patients with atrial fibrillation early and late after an acute coronary syndrome or percutaneous coronary intervention: Insights from augustus. Circulation. 2020

41. Cleary JM, Rosen LS, Yoshida K, Rasco D, Shapiro GI, Sun W. A phase 1 study of the pharmacokinetics of nucleoside analog trifluridine and thymidine phosphorylase inhibitor tipiracil (components of tas-102) vs trifluridine alone. Invest New Drugs. 2017;35:189-197

42. Lee JJ, Seraj J, Yoshida K, et al. Human mass balance study of tas-102 using (14)c analyzed by accelerator mass spectrometry. Cancer chemotherapy and pharmacology. 2016;77:515526

43. Li W, Chiba Y, Kimura T, Morioka K, Uesaka T, Ihaya A, Muraoka R. Transmyocardial laser revascularization induced angiogenesis correlated with the expression of matrix metalloproteinases and platelet-derived endothelial cell growth factor. Eur J Cardiothorac Surg. 2001;19:156-163

44. Li W, Tanaka K, Morioka K, Takamori A, Handa M, Yamada N, Ihaya A. Long-term effect of gene therapy for chronic ischemic myocardium using platelet-derived endothelial cell growth factor in dogs. J Gene Med. 2008;10:412-420

45. Yamada N, Li W, Ihaya A, et al. Platelet-derived endothelial cell growth factor gene therapy for limb ischemia. J Vasc Surg. 2006;44:1322-1328

46. Koukourakis MI, Giatromanolaki A, O'Byrne KJ, Comley M, Whitehouse RM, Talbot DC, Gatter KC, Harris AL. Platelet-derived endothelial cell growth factor expression correlates with tumour angiogenesis and prognosis in non-small-cell lung cancer. British journal of cancer. 1997;75:477-481

47. Akiyama S, Furukawa T, Sumizawa T, Takebayashi Y, Nakajima Y, Shimaoka S, Haraguchi M. The role of thymidine phosphorylase, an angiogenic enzyme, in tumor progression. Cancer science. 2004;95:851-857

48. Nakajima Y, Madhyastha R, Maruyama M. 2-deoxy-d-ribose, a downstream mediator of thymidine phosphorylase, regulates tumor angiogenesis and progression. Anti-cancer agents in medicinal chemistry. 2009;9:239-245

49. Burkhart JM, Vaudel M, Gambaryan S, Radau S, Walter U, Martens L, Geiger J, Sickmann A, Zahedi RP. The first comprehensive and quantitative analysis of human platelet protein composition allows the comparative analysis of structural and functional pathways. Blood. 2012;120:e73-82 
50. Wijten P, van Holten T, Woo LL, Bleijerveld OB, Roest M, Heck AJ, Scholten A. High precision platelet releasate definition by quantitative reversed protein profiling--brief report. Arteriosclerosis, thrombosis, and vascular biology. 2013;33:1635-1638

51. Ignatescu MC, Gharehbaghi-Schnell E, Hassan A, Rezaie-Majd S, Korschineck I, Schleef RR, Glogar HD, Lang IM. Expression of the angiogenic protein, platelet-derived endothelial cell growth factor, in coronary atherosclerotic plaques: In vivo correlation of lesional microvessel density and constrictive vascular remodeling. Arteriosclerosis, thrombosis, and vascular biology. 1999;19:2340-2347

52. Boyle JJ, Wilson B, Bicknell R, Harrower S, Weissberg PL, Fan TP. Expression of angiogenic factor thymidine phosphorylase and angiogenesis in human atherosclerosis. The Journal of pathology. 2000;192:234-242

53. Connolly GC, Khorana AA. Emerging risk stratification approaches to cancer-associated thrombosis: Risk factors, biomarkers and a risk score. Thrombosis research. 2010;125 Suppl 2:S1-7

54. Demers M, Krause DS, Schatzberg D, Martinod K, Voorhees JR, Fuchs TA, Scadden DT, Wagner DD. Cancers predispose neutrophils to release extracellular DNA traps that contribute to cancer-associated thrombosis. Proceedings of the National Academy of Sciences of the United States of America. 2012;109:13076-13081

55. Hamed EA, Zakary MM, Abdelal RM, Abdel Moneim EM. Vasculopathy in type 2 diabetes mellitus: Role of specific angiogenic modulators. J Physiol Biochem. 2011;67:339-349

56. Goldin-Lang $\mathrm{P}$, Pels $\mathrm{K}$, Tran QV, et al. Effect of ionizing radiation on cellular procoagulability and co-ordinated gene alterations. Haematologica. 2007;92:1091-1098

57. Nieswandt B, Watson SP. Platelet-collagen interaction: Is gpvi the central receptor? Blood. 2003;102:449-461

58. Kato K, Kanaji T, Russell S, et al. The contribution of glycoprotein vi to stable platelet adhesion and thrombus formation illustrated by targeted gene deletion. Blood. 2003;102:1701-1707

59. Ungerer M, Rosport K, Bultmann A, Piechatzek R, Uhland K, Schlieper P, Gawaz M, Munch G. Novel antiplatelet drug revacept (dimeric glycoprotein vi-fc) specifically and efficiently inhibited collagen-induced platelet aggregation without affecting general hemostasis in humans. Circulation. 2011;123:1891-1899

60. Schupke S, Hein-Rothweiler R, Mayer K, et al. Revacept, a novel inhibitor of platelet adhesion, in patients undergoing elective pci-design and rationale of the randomized isarplaster trial. Thromb Haemost. 2019;119:1539-1545

61. Kim S, Jin J, Kunapuli SP. Akt activation in platelets depends on gi signaling pathways. The Journal of biological chemistry. 2004;279:4186-4195

62. Mayer RJ, Van Cutsem E, Falcone A, et al. Randomized trial of tas-102 for refractory metastatic colorectal cancer. N Engl J Med. 2015;372:1909-1919

63. Yoshino T, Mizunuma N, Yamazaki K, et al. Tas-102 monotherapy for pretreated metastatic colorectal cancer: A double-blind, randomised, placebo-controlled phase 2 trial. The lancet oncology. 2012;13:993-1001

64. Doi T, Ohtsu A, Yoshino T, Boku N, Onozawa Y, Fukutomi A, Hironaka S, Koizumi W, Sasaki T. Phase i study of tas-102 treatment in japanese patients with advanced solid tumours. British journal of cancer. 2012;107:429-434 
65. Hong DS, Abbruzzese JL, Bogaard K, Lassere Y, Fukushima M, Mita A, Kuwata K, Hoff PM. Phase i study to determine the safety and pharmacokinetics of oral administration of tas-102 in patients with solid tumors. Cancer. 2006;107:1383-1390 


\section{Figure legends}

Figure 1. TYMP binds to its partners through their SH3-domain. A. pCDNA6/his-hTYMP plasmid vector, either alone or combined with pEGFP-N1-hLyn-GFP vector, was transfected into Cos-7 cells, and His-Tagged TYMP was pulled down using His Mag Sepharose Ni beads. Inputs and elutes were blotted using anti-Lyn antibody. B. pCDNA6/his-hTYMP and pEBGGST-SH3(hLyn) were co-transfected into Cos-7 cells and the lysate was used for GST pull-down assay and elute was used for blotting human TYMP. In both panels, I: input; B: blank, E: elute. Blots represents 2-3 repeats.

Figure 2. Cellix Vena8 Fluoro+ chamber-based platelet aggregation assay. The flow chambers were coated with $10 \mu \mathrm{g} / \mathrm{ml}$ collagen overnight. A. Whole blood drew from WT and $\mathrm{Tymp}^{-/-}$mice were perfused into the chamber in a flow shear $65 \mathrm{dyn} / \mathrm{cm}^{2}$. B. WT whole blood treated with $50 \mu \mathrm{M}$ TPI in saline or saline alone were perfused into the chamber at a shear 65 dyn $/ \mathrm{cm}^{2}$. Graphs show areas covered by platelets at 3 minutes after perfusion.

Figure 3. Inhibition of TYMP in vitro inhibits platelet activation. A. WT and Tymp ${ }^{-/-}$ platelets in PRP were treated with $50 \mu \mathrm{M}$ TPI for 2 minutes and then CRP-induced platelet aggregation was assessed. B \& C. WT platelets in PRP were treated with different concentration of TPI for 2 minutes and then collagen $(1 \mu \mathrm{g} / \mathrm{ml})$ induced platelet activation was assessed. D. WT and Tymp $^{-/}$platelets in PRP were treated with $50 \mu \mathrm{M}$ TPI for 2 minutes and then $2.5 \mu \mathrm{M}$ ADP-induced platelet aggregation was assessed. E. WT and Tymp ${ }^{-/}$platelets in PRP were treated with $2.5 \mu \mathrm{M}$ ADP for the indicated times and then AKT activation were evaluated. Blot represents two repeats. F. WT platelets in PRP pooled from 10 mice were divided into 8 parts. Four parts were treated with $50 \mu \mathrm{M}$ TPI and another 4 parts were treated with saline as controls before they were treated with $2.5 \mu \mathrm{M}$ ADP for the indicated times. Platelet lysates were used for assessing AKT phosphorylation. G. WT platelet in PRP were divided into 8 groups, treated with saline or $50 \mu \mathrm{M}$ TPI, and then treated with $2.5 \mu \mathrm{M}$ ADP for the indicated times. Platelet surface p-selectin expression was analyzed by flow cytometry and data were shown as ratio of control ( 0 minute). $\mathrm{N}=3$.

Figure 4. TYMP deficiency in vivo inhibits thrombosis. 8-10 weeks WT and Tymp ${ }^{-/-}$mice in both genders were subjected to the $7.5 \% \mathrm{FeCl}_{3}$-induced thrombosis model. A \& $\mathbf{B}$. Role of TYMP deficiency on thrombosis in female mice. C \& D. TYMP deficiency on thrombosis regardless of gender. Time to thrombosis (A and $\mathbf{C}$ ) and frequency of vessel opening (B and D) were analyzed in WT, Tymp $^{+/}$, and Tymp $^{-/-}$mice.

Figure 5. TPI inhibits thrombosis under both normal and hyperlipidemia conditions without disturbing hemostasis. WT mice were treated with TPI by intraperitoneal (IP) injection (A) or intravenous injection (C), and oral administration (D \& E) at the indicated doses and then subjected to the $\mathrm{FeCl}_{3}$ induced thrombosis model. Tail bleeding time was also assessed in mice received TPI IP injection (B). F, G and $\mathbf{H}$, WT mice fed with a western diet (WD, TD.88137) for 4 weeks were subjected to the thrombosis model and thrombosis in age-matched WT mice were used as control. F, representative images from each group; supplementary videos I-III are shown online. G, mean blood flow cessation time. H, Percentage of mice without flow stoppage. 
Figure 6. Comparison the therapeutic and side effect of TPI with aspirin and clopidogrel. A. WT mice were gavage fed with different doses of aspirin and clopidogrel as well as $1 \mathrm{mg} / \mathrm{kg}$ TPI in saline and then subjected to the $7.5 \% \mathrm{FeCl}_{3}$ induced thrombosis model. WT mice received saline were used as control. * \&\#, p>0.05 vs. WT. B. Representative video images for mice received $1 \mathrm{mg} / \mathrm{kg}$ TPI, $1 \mathrm{mg} / \mathrm{kg}$ aspirin, and $2.5 \mathrm{mg} . \mathrm{kg}$ clopidogrel. $\boldsymbol{C} \boldsymbol{\&} \boldsymbol{D}$. Bleeding time in mice received effect doses of aspirin $(1.0 \mathrm{mg} / \mathrm{kg})$ and clopidogrel $(2.5 \mathrm{mg} / \mathrm{kg})$ was compared with mice received $1 \mathrm{mg} / \mathrm{kg}$ TPI.

Figure 7. TPI is a quick-acting anti-thrombotic drug that reduces the effective dose of tPA on preventing occlusive thrombi formation. Thrombosis in WT mice were initiated with 7.5\% $\mathrm{FeCl}_{3}$ and 5 minutes later, TPI (A), or tPA (B), or the combination of TPI and TPA (C) in saline at the indicated doses were bolus injected into mice through a jugular vein catheter, and thrombosis times were assessed. D. Representative images for mice received $0.25 \mathrm{mg} / \mathrm{kg} \mathrm{tPA}$ and $75 \mu \mathrm{g} / \mathrm{kg}$ TPI bolus injection.

Figure 8. Combination of low dose aspirin and TPI is a new, safe dual antiplatelet therapy. $\boldsymbol{A} \boldsymbol{\&} \boldsymbol{B}$. WT mice were gavage fed with either aspirin $0.5 \mathrm{mg} / \mathrm{kg} / \mathrm{day}$, or a combination of aspirin $0.5 \mathrm{mg}$-TPI $50 \mu \mathrm{g} / \mathrm{kg} /$ day in $200 \mu \mathrm{L}$ saline for 7 days. Then the mice were subjected to the $7.5 \%$ $\mathrm{FeCl}_{3}$ induced carotid artery injury thrombosis model and time to occlusive thrombus formation were determined. $\boldsymbol{C}$. Tail bleeding time was assessed using the mice received aspirin $0.5 \mathrm{mg}$-TPI $50 \mathrm{mg} / \mathrm{kg} /$ day after the thrombosis study and compared with age-matched WT mice without any treatment. 


\section{Figure 1}
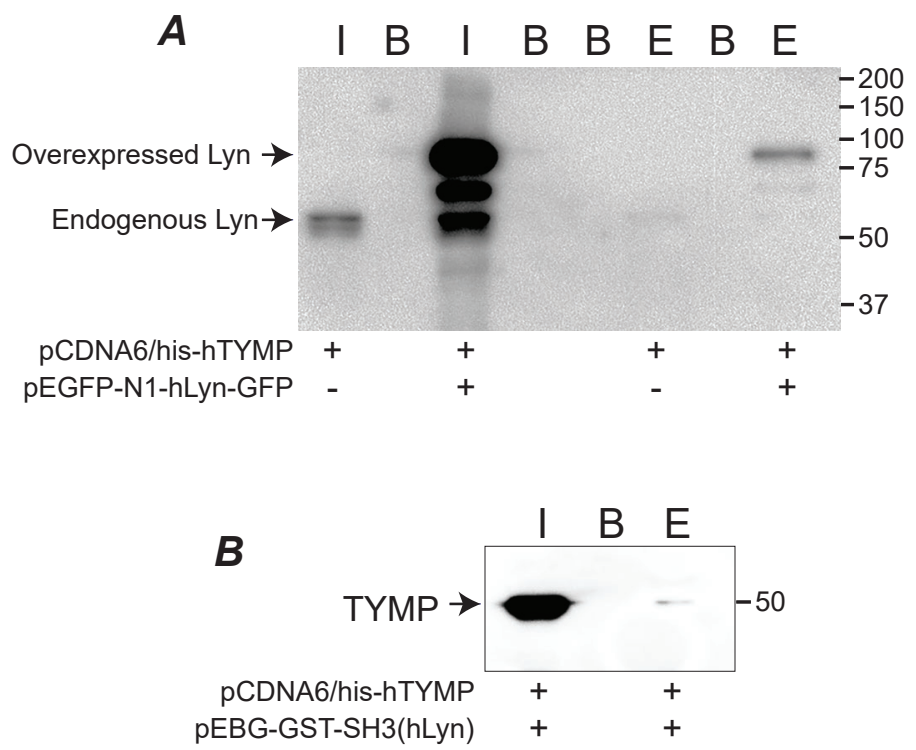

Fig. 1. TYMP binds to its partners through their SH3-domain. A. pCDNA6/his-hTYMP plasmid vector, either alone or combined with pEGFP-N1-hLyn-GFP vector, was transfected into Cos-7 cells, and His-Tagged TYMP was pulled down using His Mag Sepharose Ni beads. Inputs and elutes were blotted using anti-Lyn antibody. B. pCDNA6/his-hTYMP and pEBG-GST-SH3(hLyn) were co-transfected into Cos-7 cells and the lysate was used for GST pull-down assay and elute was used for blotting human TYMP. In both panels, I: input; B: blank, E: elute. Blots represents 2-3 repeats. 
Figure 2
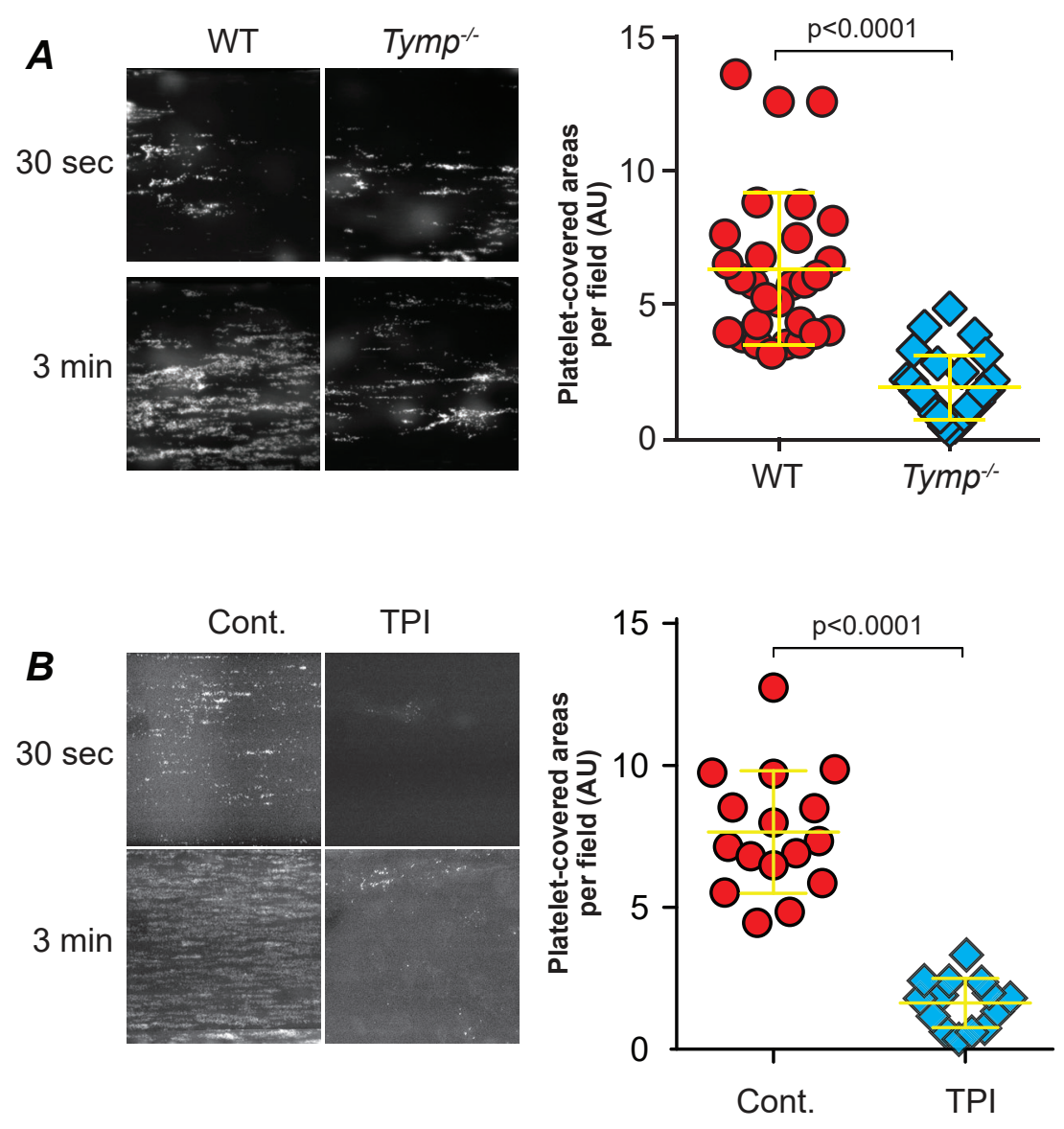

Fig. 2. Cellix Vena8 Fluoro+ chamber-based platelet aggregation assay. The flow chambers were coated with $10 \mu \mathrm{g} / \mathrm{ml}$ collagen overnight. $\boldsymbol{A}$. Whole blood drew from WT and Tymp $^{-/-}$mice were perfused into the chamber in a flow shear $65 \mathrm{dyn} / \mathrm{cm}^{2}$. B. WT whole blood treated with $50 \mu \mathrm{M}$ TPI in saline or saline alone were perfused into the chamber at a shear $65 \mathrm{dyn} / \mathrm{cm}^{2}$. Graphs show areas covered by platelets at 3 minutes after perfusion. 

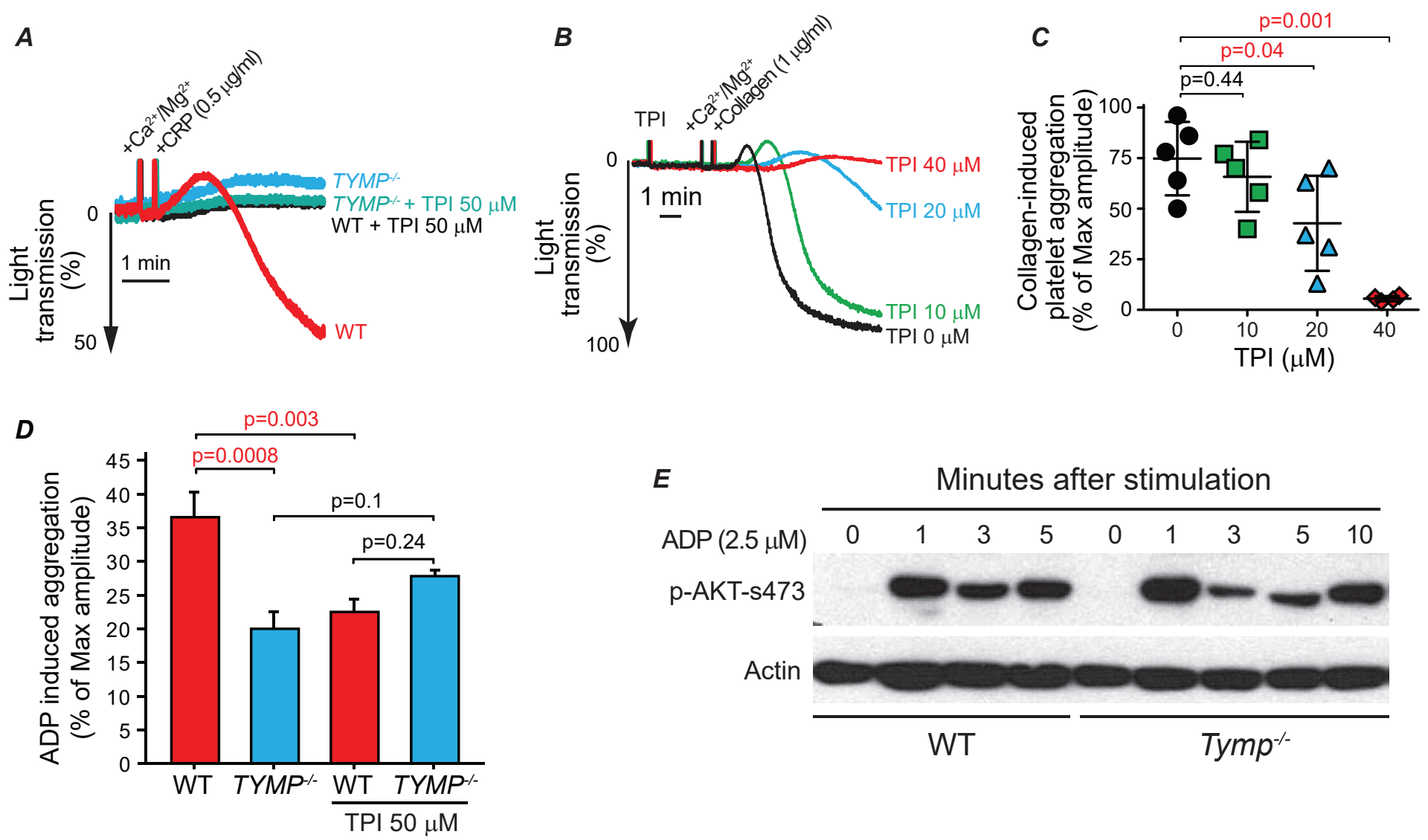

E Minutes after stimulation
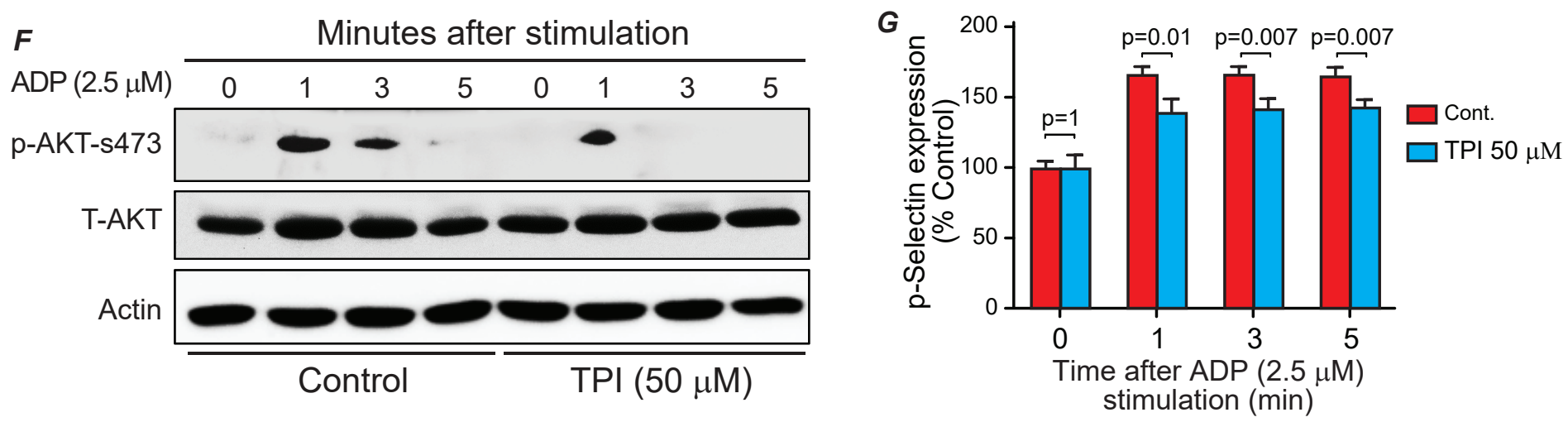

Fig. 3. Inhibition of TYMP in vitro inhibits platelet activation. $A$. WT and Tymp ${ }^{-/}$platelets in PRP were treated with $50 \mu \mathrm{M}$ TPI for 2 minutes and then CRP-induced platelet aggregation was assessed. $\boldsymbol{B} \& \boldsymbol{C}$. WT platelets in PRP were treated with different concentration of TPI for 2 minutes and then collagen $(1 \mu \mathrm{g} / \mathrm{ml})$ induced platelet activation was assessed. D. WT and Tymp ${ }^{-/}$platelets in PRP were treated with $50 \mu \mathrm{M}$ TPI for 2 minutes and then $2.5 \mu \mathrm{M}$ ADP-induced platelet aggregation was assessed. E. WT and Tymp ${ }^{-/}$platelets in PRP were treated with $2.5 \mu \mathrm{M}$ ADP for the indicated times and then AKT activation were evaluated. Blot represents two repeats. $\boldsymbol{F}$. WT platelets in PRP pooled from 10 mice were divided into 8 parts. Four parts were treated with $50 \mu \mathrm{M} \mathrm{TPI}$ and another 4 parts were treated with saline as controls before they were treated with $2.5 \mu \mathrm{M}$ ADP for the indicated times. Platelet lysates were used for assessing AKT phosphorylation. G. WT platelet in PRP were divided into 8 groups, treated with saline or $50 \mu \mathrm{M} \mathrm{TPI}$, and then treated with $2.5 \mu \mathrm{M}$ ADP for the indicated times. Platelet surface $p$-selectin expression was analyzed by flow cytometry and data were shown as ratio of control ( 0 minute). $\mathrm{N}=3$. 


\section{Figure 4}

\section{$\boldsymbol{A}$}
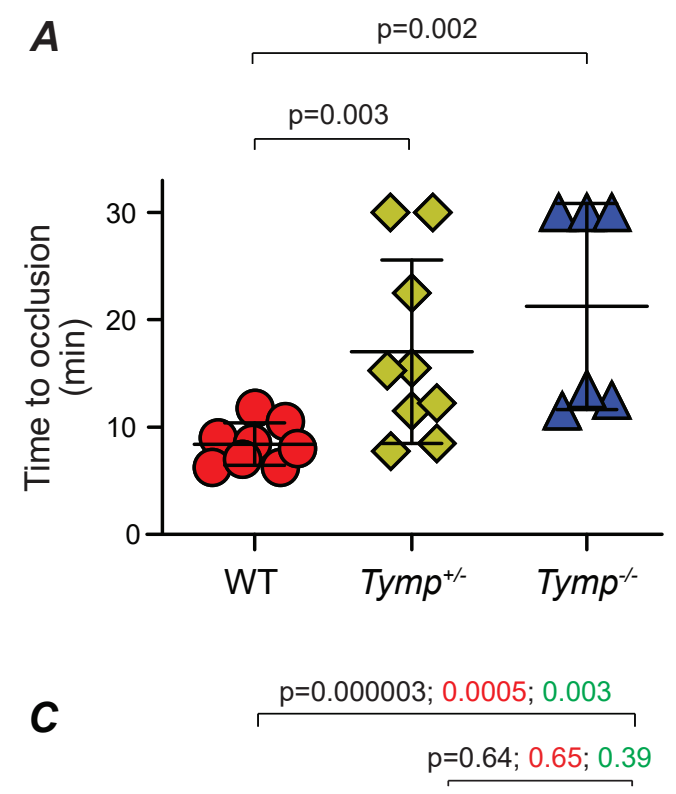

$p=0.00002 ; 0.0001 ; 0.01$

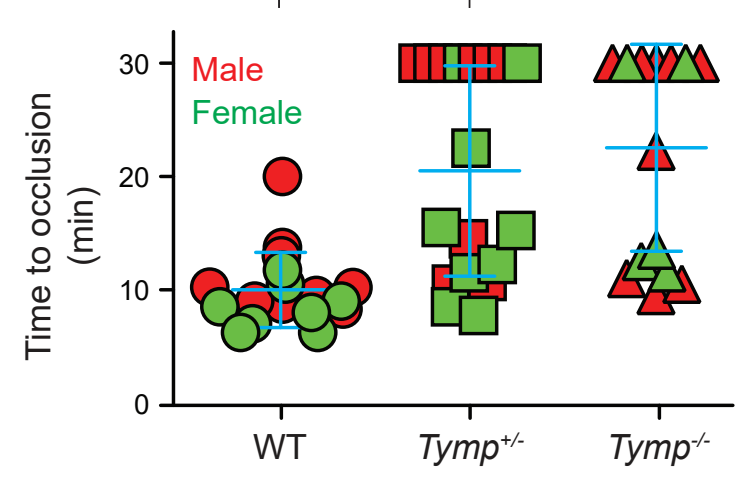

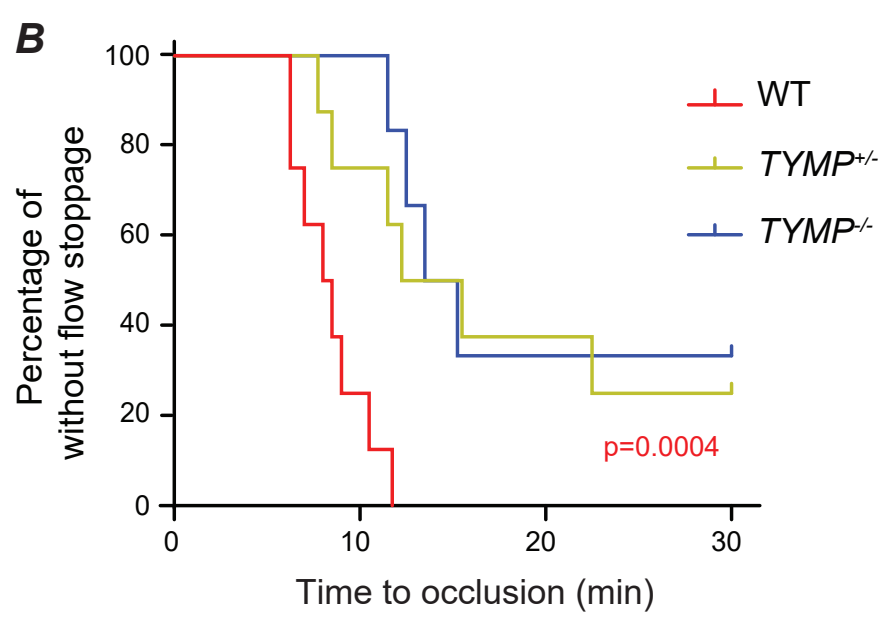

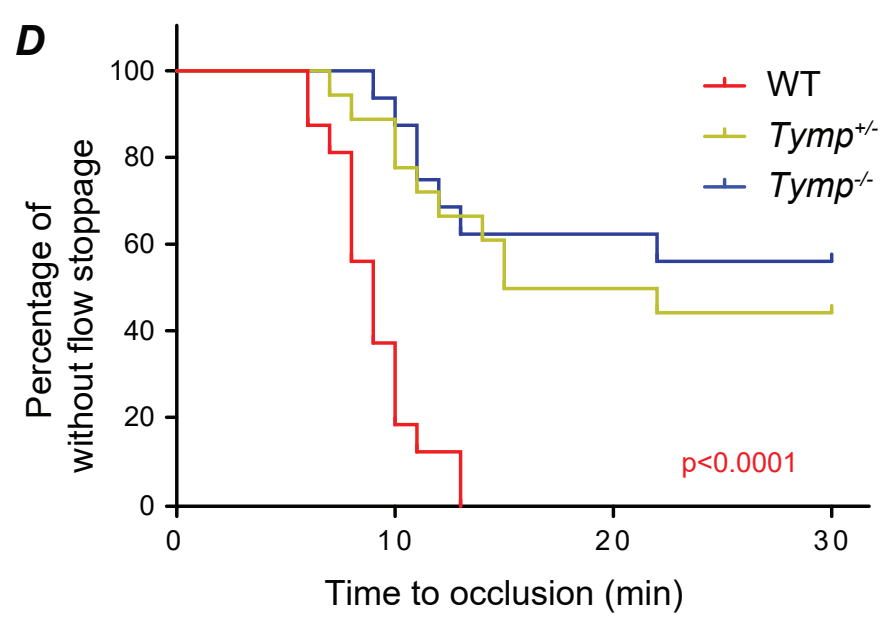

Fig. 4. TYMP deficiency in vivo inhibits thrombosis. 8-10 weeks WT and Tymp ${ }^{-/}$mice in both genders were subjected to the $7.5 \% \mathrm{FeCl} 3$-induced thrombosis model. $\boldsymbol{A}$ \& $\boldsymbol{B}$. Role of TYMP deficiency on thrombosis in female mice. $\boldsymbol{C} \& \boldsymbol{D}$. TYMP deficiency on thrombosis regardless of gender. Time to thrombosis ( $A$ and $C$ ) and frequency of vessel opening ( $B$ and $D$ ) were analyzed in WT, Tymp ${ }^{+/-}$and Tymp ${ }^{-/-}$mice. 

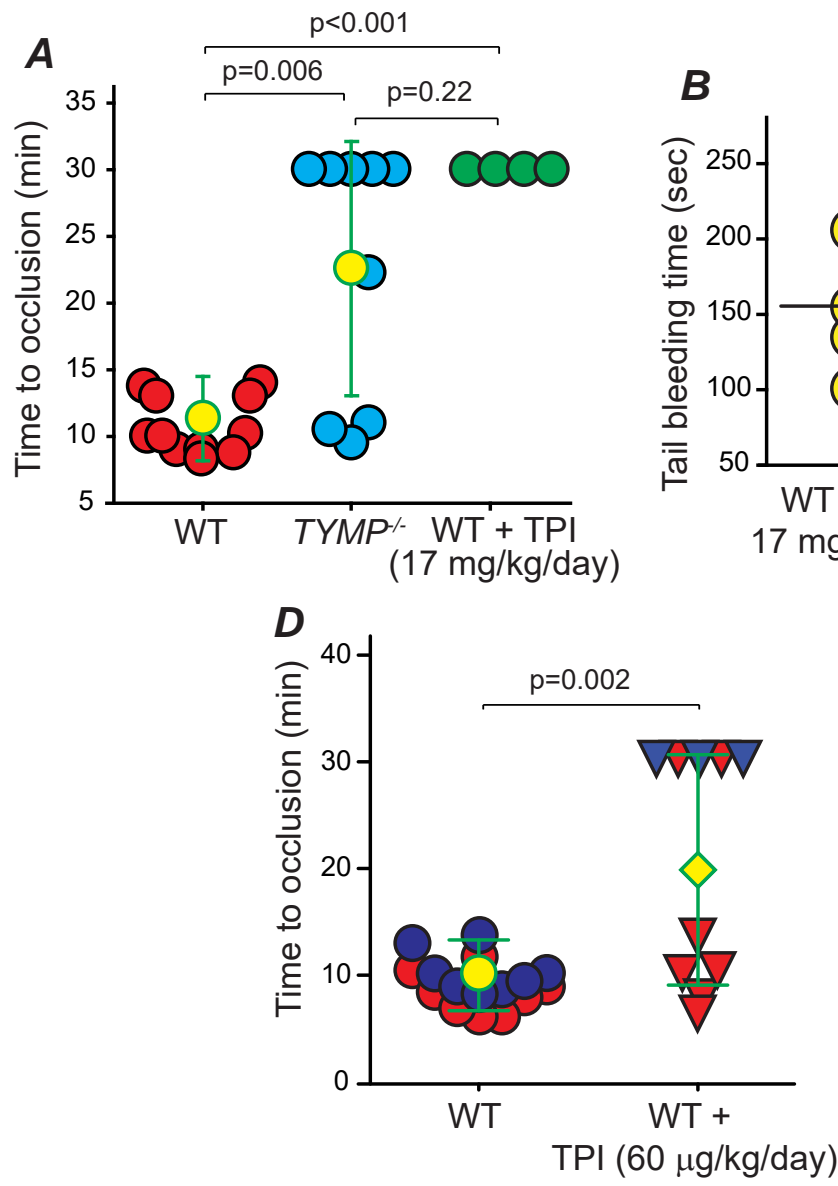
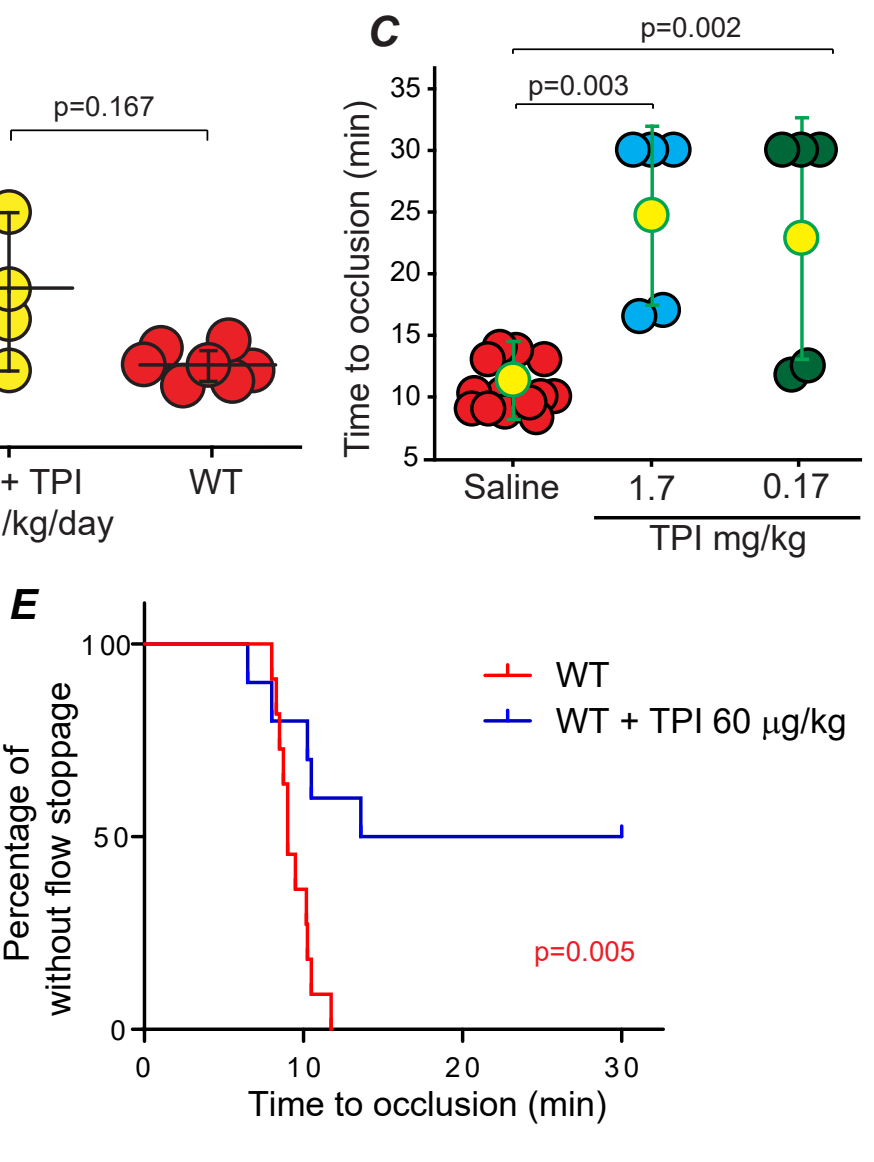

E
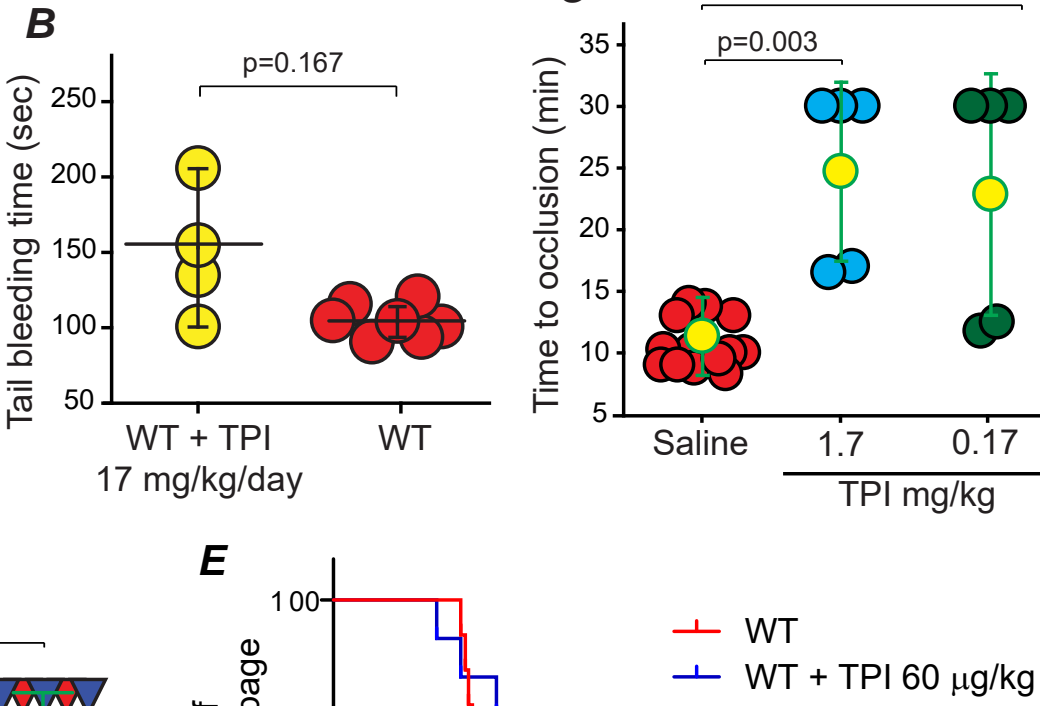

$$
\boldsymbol{F}
$$

After $\mathrm{FeCl}_{3}$ injury (min)
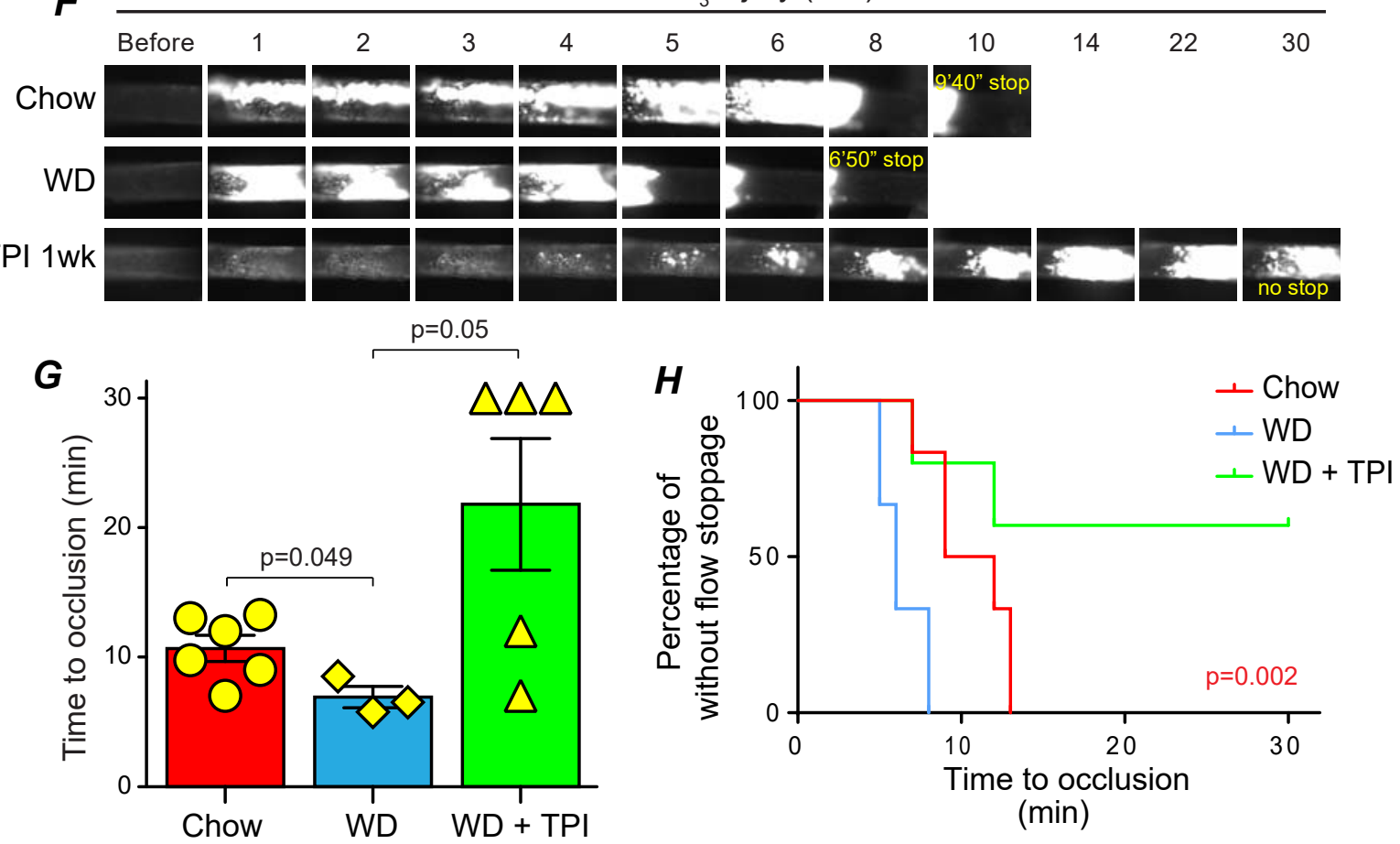

Fig. 5. TPI inhibits thrombosis under both normal and hyperlipidemia conditions without disturbing hemostasis. WT mice were treated with TPI by intraperitoneal (IP) injection (A) or intravenous injection (C), and oral administration $(\boldsymbol{D} \& \boldsymbol{E})$ at the indicated doses and then subjected to the $\mathrm{FeCl}_{3}$ induced thrombosis model. Tail bleeding time was also assessed in mice received TPI IP injection $(\boldsymbol{B})$. $\boldsymbol{F}, \boldsymbol{G}$ and $\boldsymbol{H}$, WT mice fed with a western diet (WD, TD.88137) for 4 weeks were subjected to the thrombosis model and thrombosis in age-matched WT mice were used as control. $\boldsymbol{F}$, representative images from each group; supplementary videos I-III are shown online. $\boldsymbol{G}$, mean blood flow cessation time. $\boldsymbol{H}$, Percentage of mice without flow stoppage. 


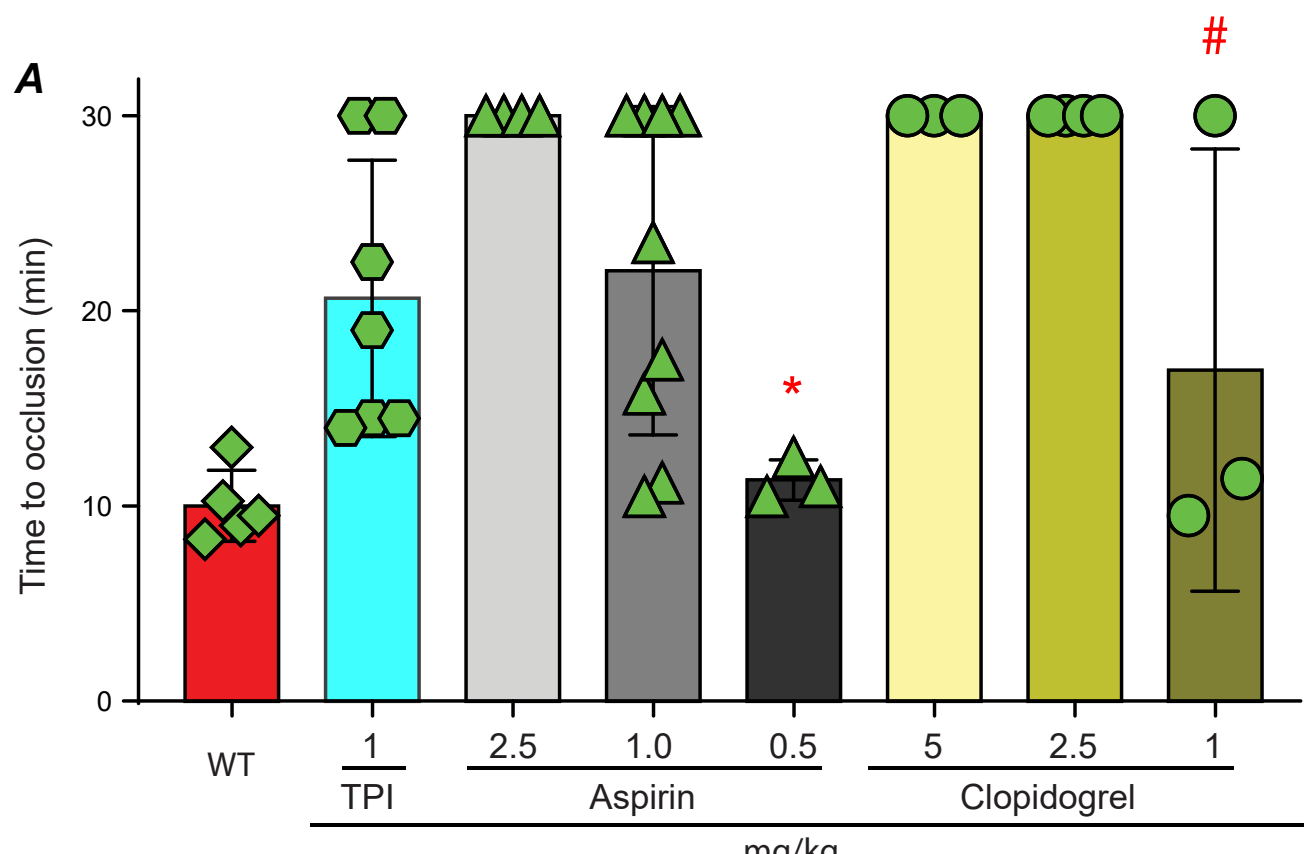

B After $\mathrm{FeCl}_{3}$ injury (min)

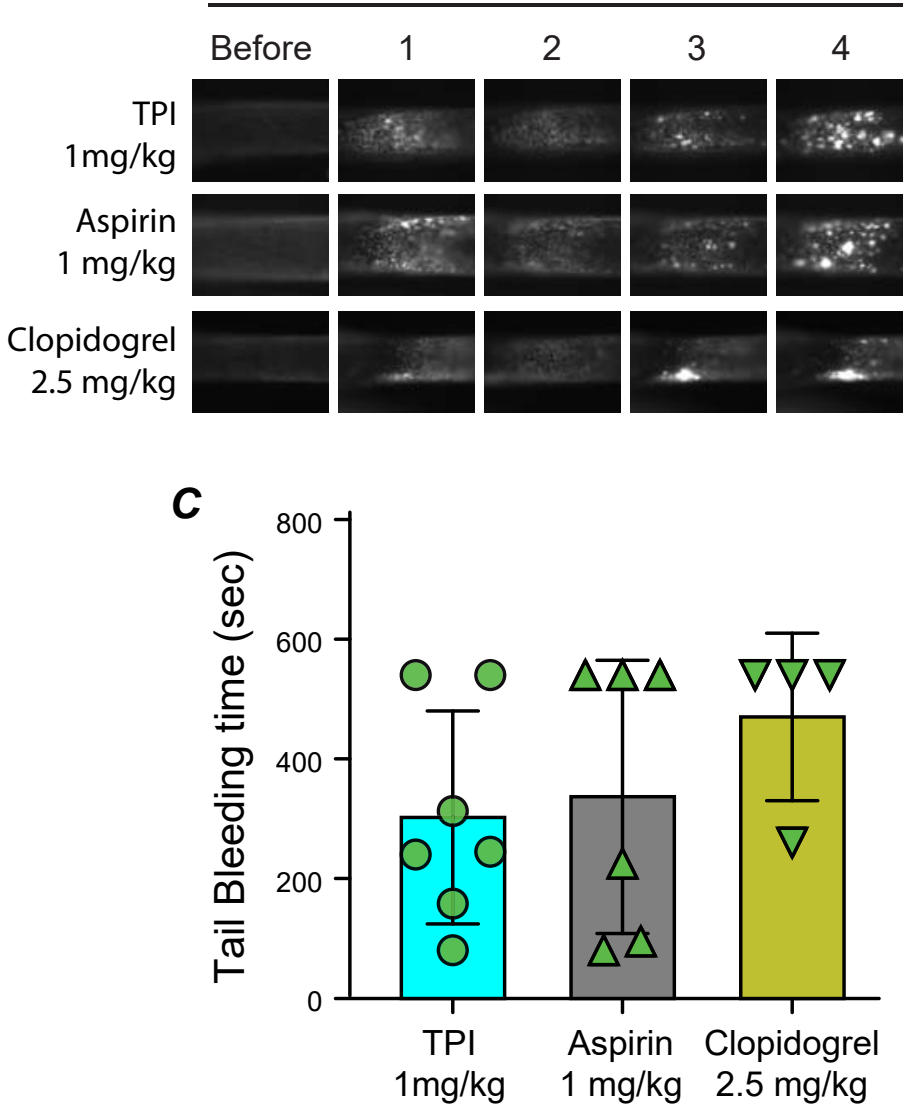

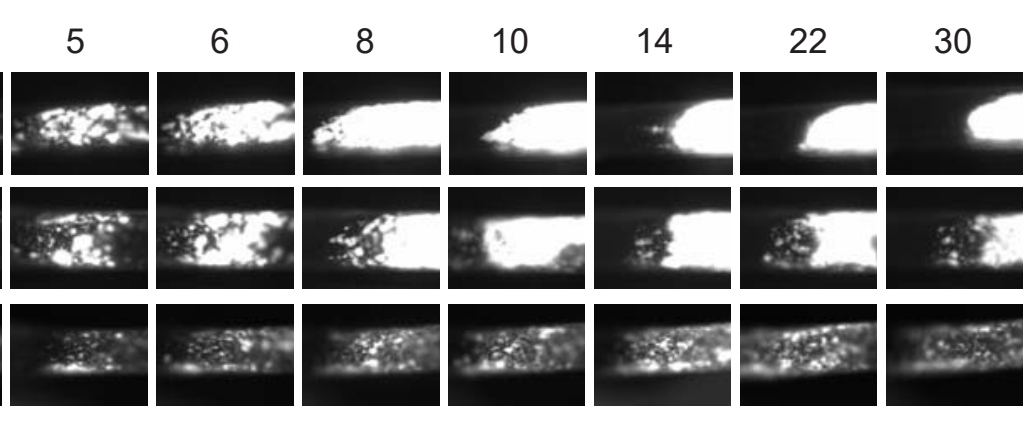

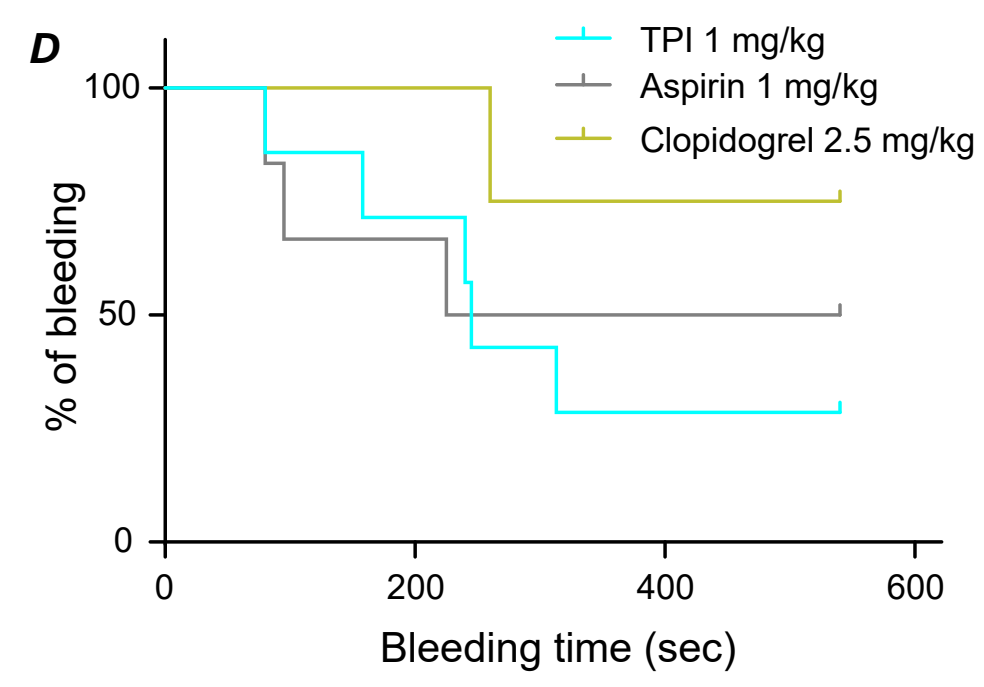

Fig. 6. Comparison the therapeutic and side effect of TPI with aspirin and clopidogrel. $A$. WT mice were gavage fed with different doses of aspirin and clopidogrel as well as $1 \mathrm{mg} / \mathrm{kg}$ TPI in saline and then subjected to the $7.5 \% \mathrm{FeCl}_{3}$ induced thrombosis model. WT mice received saline were used as control. * \&\#, p>0.05 vs. WT. B. Representative video images for mice received $1 \mathrm{mg} / \mathrm{kg} \mathrm{TPI}, 1 \mathrm{mg} / \mathrm{kg}$ aspirin, and $2.5 \mathrm{mg} . \mathrm{kg}$ clopidogrel. $\boldsymbol{C} \& \boldsymbol{D}$. Bleeding time in mice received effective doses of aspirin $(1.0 \mathrm{mg} / \mathrm{kg})$ and clopidogrel $(2.5 \mathrm{mg} / \mathrm{kg}$ ) was compared with mice received $1 \mathrm{mg} / \mathrm{kg} \mathrm{TPI}$. 
Figure 7
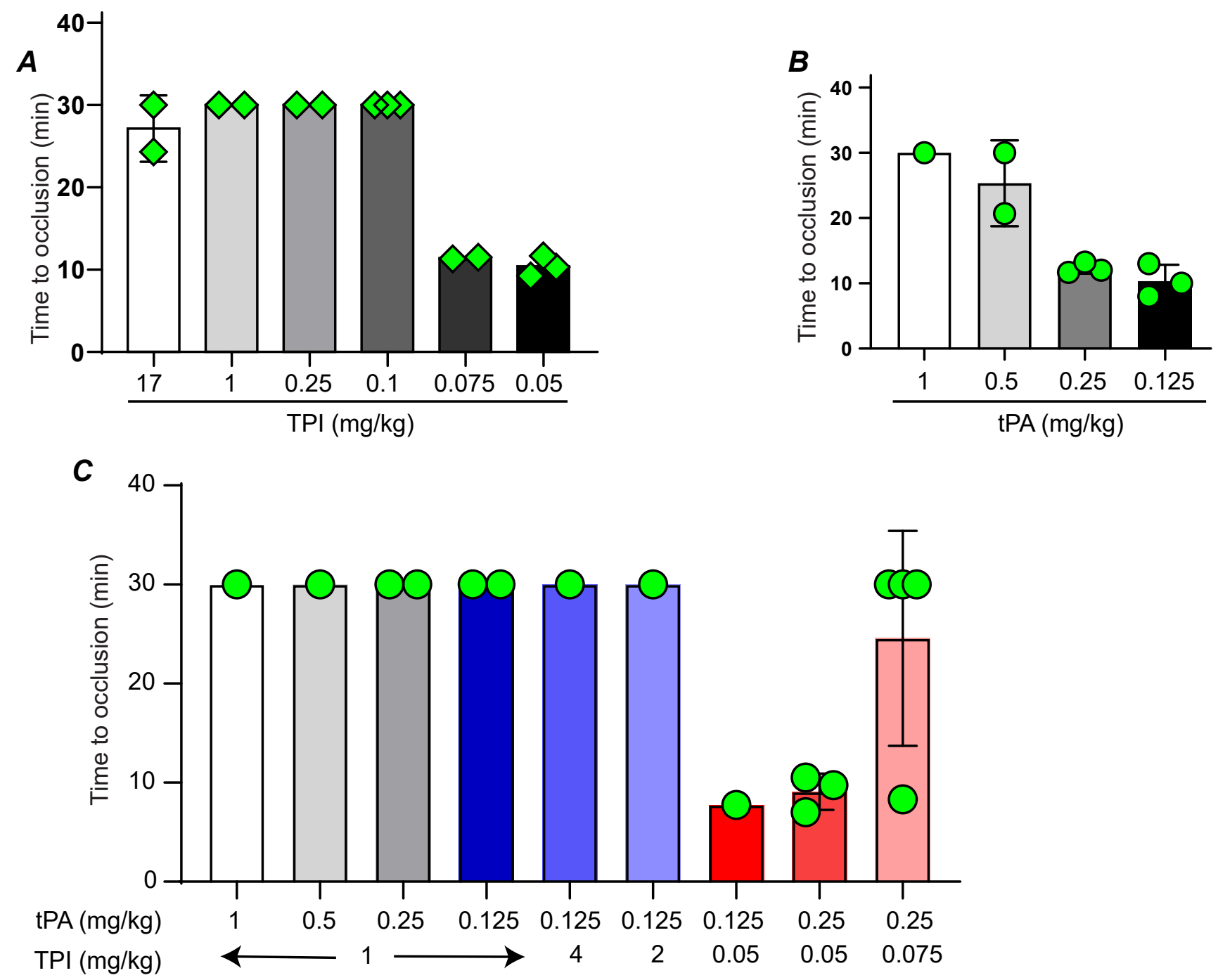

D

After $\mathrm{FeCl}_{3}$ injury (min)

\begin{tabular}{|c|c|c|c|c|c|c|c|c|c|c|c|c|}
\hline Before & 1 & 2 & 3 & 4 & 5 & 6 & 7 & 8 & 10 & 14 & 22 & 30 \\
\hline
\end{tabular}

Injection of tPA/TPI

Fig. 7. TPI is a quick-acting anti-thrombotic drug that reduces the effective dose of tPA on preventing occlusive thrombi formation. Thrombosis in WT mice were initiated with $7.5 \% \mathrm{FeCl}_{3}$ and 5 minutes later, $\operatorname{TPI}(\boldsymbol{A})$, or TPA $(\boldsymbol{B})$, or the combination of TPI and TPA $(\boldsymbol{C})$ in saline at the indicated doses were bolus injected into mice through a jugular vein catheter, and thrombosis times were assessed. $\boldsymbol{D}$. Representative images for mice received $0.25 \mathrm{mg} / \mathrm{kg}$ tPA and $75 \mu \mathrm{g} / \mathrm{kg}$ TPI bolus injection. 
Figure 8
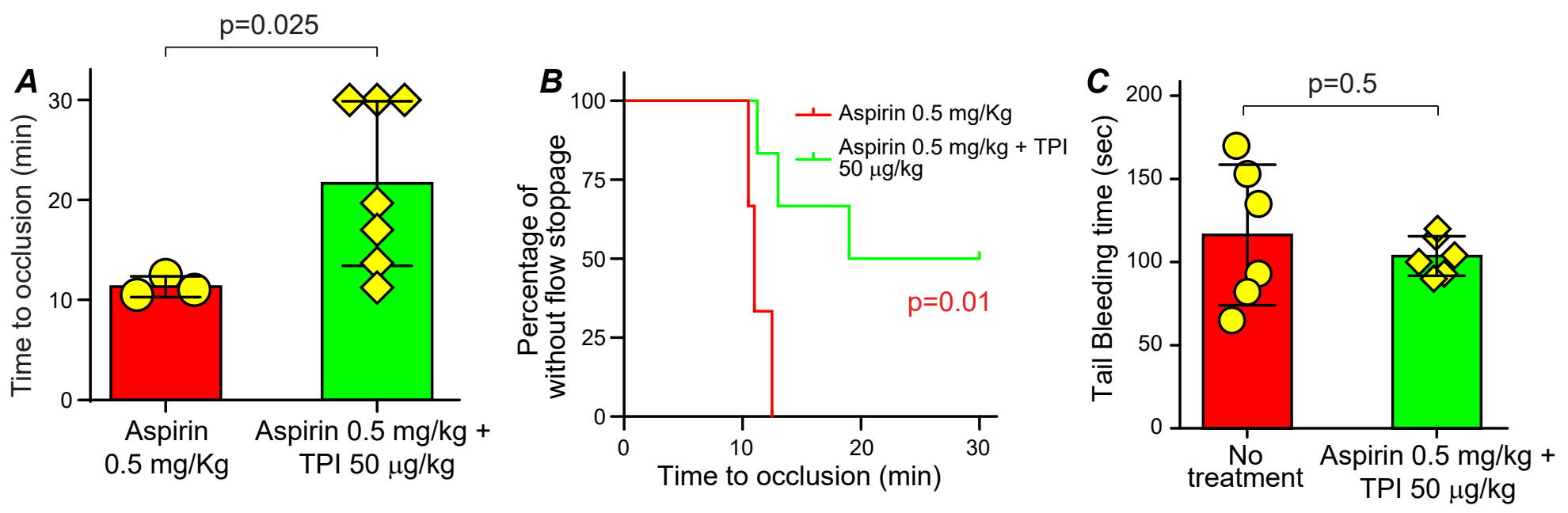

Fig. 8. Combination of low dose aspirin and TPI is a new, safe dual antiplatelet therapy. $A \& B$. WT mice were gavage fed with either aspitin $0.5 \mathrm{mg} / \mathrm{kg} / \mathrm{day}$, or a combination of aspirin $0.5 \mathrm{mg}-\mathrm{TPI} 50 \mu \mathrm{g} / \mathrm{kg} / \mathrm{day}$ in $200 \mu \mathrm{L}$ saline for 7 days. Then the mice were subjected to the $7.5 \% \mathrm{FeCl}_{3}$ induced carotid artery injury thrombosis model and time to occlusive thrombus formation were determined. $\boldsymbol{C}$. Tail bleeding time was assed using the mice received aspirin $0.5 \mathrm{mg}-\mathrm{TPI} 50 \mu \mathrm{g} / \mathrm{kg} /$ day after the thrombosis study and compared with age-matched WT mice without any treatment. 


\section{SUPPLEMENTAL MATERIAL}

\section{Materials}

All platelet agonists including ADP, collagen and thrombin was purchased from Chronolog (Havertown, PA). Collagen related peptide (CRP) was a gift from Dr. Peter Newman (Blood Research Institute, WI). Antibodies to phosphorylated AKT and total AKT were purchased from Cell Signaling Technology (Dallas, TX). FITC-conjugated P-selectin antibody and the isotype control IgG were purchased from BD Biosciences (San Jose, CA). All other chemical reagents were purchased from Sigma (St. Louis, MO) except where specifically indicated.

\section{Experiment animals}

Wild type C57BL/6 mice (WT) were purchased from Jackson Laboratory (Bar Harbor, ME). Tymp ${ }^{-/-}$mouse strain was generated by Dr. Hirano's laboratory as mentioned before, ${ }^{1,2}$ and maintained in our lab by inbreeding. Breeder mice were genotyped before mating and all mice were given identity using ear tags at the time of weaning. Mice in eight to twelve weeks old in both genders were used in this study. All procedures and manipulations of animals have been approved by the Institutional Animal Care and Use Committee of Marshall University (IACUC\#: 1033528).

\section{Murine carotid artery thrombosis model and tail bleeding assay}

Detailed ferric chloride $\left(\mathrm{FeCl}_{3}\right)$ induced carotid artery thrombosis model has been described before. ${ }^{3,4}$ Briefly, the mouse was anesthetized with ketamine (100 mg/kg) and xylazine (10 mg/kg). Vessel injury was induced by topically applying a piece of filter paper (1 x $2 \mathrm{~mm})$ saturated with $7.5 \% \mathrm{FeCl}_{3}$ solution to the carotid artery for 1 minute. Thrombi formation was observed in real-time using an intravital microscope (Leica DM6 FS) and video images were captured with a 14-bit Retiga R1 CCD color digital camera (Teledyne QImaging, Surrey, BC, Canda) and a STP7-S-STDT Streampix 7 software (Norpix, Montreal, Canada). The endpoints were set as: 1) blood flow has ceased for > 30 seconds; or 2) occlusion is not seen after 30 minutes of $\mathrm{FeCl}_{3}$ injury. In this case, 30 minutes was assigned to that mouse for the statistical analysis.

In some experiments, a jugular vein catheter prepared with P-10 tubing was placed for drug administration after thrombus initiation. In this case, platelets were labeled by perfusion of $50 \mu \mathrm{L}$ Rhodamine 6G solution through the jugular vein catheter and then thrombosis was initiated as mentioned above. TPI (62.5 - 2,000 $\mu \mathrm{g} / \mathrm{kg})$, tPA (125-1,000 $\mu \mathrm{g} / \mathrm{kg})$, or combination of different doses of TPI and tPA were delivered to the mice 5 minutes after thrombus initiation. Thrombus formation was continually monitored using endpoints as mentioned above.

Tail bleeding assay was conducted in some mice immediately after the thrombosis study as well as in some mice that were not used for the in vivo thrombosis study. ${ }^{5}$ Briefly, the tail was cut at the site of $1 \mathrm{~cm}$ from the tip with a sharp razor blade and immediately immersed into warm saline $\left(37^{\circ} \mathrm{C}\right)$ and cessation time of bleeding was recorded. If bleeding showed no stoppage after 9 minutes, which is about three times longer than the average bleeding time that we observed in the normal WT mice, 9 minutes was assigned to that mouse for statistical analysis. Red blood cells collected from the bleeding assay were separated by centrifugation, lysed in RBC lysis buffer, and hemoglobin amount was measured with a wavelength of $550 \mathrm{~nm}$. 


\section{Mouse platelet isolation}

Mice were anesthetized with ketamine/xylazine (100/10 mg/kg), and whole blood were drawn through inferior vena cava (IVC) puncture using $0.109 \mathrm{M}$ sodium citrate as an anticoagulant. ${ }^{1,6}$ Modified Tyrode’s buffer (in mM: $137 \mathrm{NaCl}, 2.7 \mathrm{KCl}, 12 \mathrm{NaHCO}_{3}, 0.4$ $\mathrm{NaH}_{2} \mathrm{PO}_{4}, 5$ HEPES, 0.1\% glucose and 0.35\% BSA, pH 7.2), 0.7 volumes of the whole blood, was added, and platelet-rich plasma (PRP) was separated by centrifugation at $100 \mathrm{~g}$ for $10 \mathrm{~min}$, and transferred into a new tube. The buffer coat and red blood cells sedation were further centrifuged at 1,000 g for 6 minutes to obtain platelet-poor-plasma (PPP). Platelets number were counted with a hemocytometer.

\section{Platelet aggregation assay}

Murine platelets in PRP were adjusted to a concentration of $2.5 \times 10^{8} / \mathrm{ml}$ using PPP. Platelet aggregation was performed using a standard turbidimetric assays monitored by an Aggregometer (Model 700, Chrono-log, Havertown, PA) and data were acquisted using Aggrolink8 version $1.29 .^{6-8}$ Sample were stirred constantly at 1,200 RPM at $37^{\circ} \mathrm{C}$. Light transmission was monitored over time, and aggregation was quantified, with $100 \%$ aggregation corresponding to $100 \%$ light transmission. In some experiments, platelets were pretreated with different concentration of TPI for 2 min (or indicated times) before adding $\mathrm{CaCl}_{2} / \mathrm{MgCl}_{2}$ for a final concentration of $1 \mathrm{mM}$ and agonists as indicated in the Results. Same volume of vehicle (DMSO or saline)-treated platelets was used as controls.

\section{Cellix flow chamber-based platelet adhesion and aggregation assay}

Cellix flow chambers were coated with collagen $10 \mu \mathrm{g} / \mathrm{mL}$ in PBS for overnight and then blocked with $0.1 \%$ BSA in PBS for 30 minutes at room temperature. Whole blood was drawn from mouse IVC using $0.109 \mathrm{M}$ sodium citrate as an anticoagulant and stained with Rhodamine $6 \mathrm{G}$ in a final concentration of $0.1 \mu \mathrm{g} / \mu \mathrm{L}$. The whole blood was repleted with $\mathrm{CaCl}_{2} / \mathrm{MgCl}_{2}$ in a final concentration of $1 \mathrm{mM}$ immediately before perfused through the flow chamber. In some experiments, whole blood drew from one mouse was divided into two parts (450 $\mu \mathrm{L} / \mathrm{part}$ ), and one part was treated with TPI in a final concentration of $50 \mu \mathrm{M}$ for 5 minutes, repleted with $\mathrm{CaCl}_{2} / \mathrm{MgCl}_{2}$, and then perfused into the chamber. Another part treated with saline was used as control. The flow shear was set at $65 \mathrm{dyn} / \mathrm{cm}^{2}$. Platelet accumulation on the coated chamber surface was monitored and recorded in real time for 3 minutes with an Invert Microscope (Leica DM8) with a video camera operated by the CaptaVision+ v2.1 software (ACCU-SCOPE®, Commack, NY). The flow chambers were washed with PBS for additional 3 minutes to remove the free blood cells and then images at the six marker-sites designed by the manufacture were taken and fluorescent intensity was measured using Image J (Fiji, NIH).

\section{Compare the therapeutic effect of TPI with Aspirin and clopidogrel}

8 to 10 week old male WT mice was gavage fed with TPI $(0.06,0.17$, and $1 \mathrm{mg} / \mathrm{Kg})$, Aspirin (0.5, 1, and $2.5 \mathrm{mg} / \mathrm{Kg}$ ), or clopidogrel (1, 2.5, and $5 \mathrm{mg} / \mathrm{Kg}$ ), or the combination of aspirin $0.5 \mathrm{mg} / \mathrm{kg}$ and TPI $50 \mu \mathrm{g} / \mathrm{kg}$, once daily for one week, and then the mice were subjected to the thrombosis model. Tail bleeding assay was conducted on these mice immediately after the thrombosis study. In another set of study, WT mice received intraperitoneal injection of TPI 14 $\mathrm{mg} / \mathrm{kg}$ or vehicle for 3 days, or gavage feeding with TPI (0.06 mg/Kg/day) for 14 to 30 days, and then the mice were subjected to the thrombosis model and tail bleeding assay. 


\section{Examine the effect of TYMP inhibition on thrombosis under hyperlipemia}

Increased platelet reactivity and thrombosis in dyslipidemia has been observed in multiple murine models of in vivo thrombosis as well as in clinical patients. To determine whether TPI attenuates the hyperlipidemia-enhanced thrombotic diathesis, we fed WT mice with a western diet (TD.88137) for 4 weeks to enhance hyperlipidemia. For some mice, the diet was changed to a customized diet TD.190501, which has the same component as TD.88137 but contains TPI $10.7 \mathrm{mg} / \mathrm{Kg}$, for the last 7 days. Mice fed with TD.190501 received TPI in a dose of about $1 \mathrm{mg} / \mathrm{Kg} /$ day. These mice were then subjected to the thrombosis study using the $7.5 \%$ $\mathrm{FeCl}_{3}$ induced thrombosis model. Age-matched mice on chow diet were used as control.

\section{Immunoblotting assay-based evaluation of platelet signaling activation}

Platelets in PRP were pooled from 8-10 mice, and platelet concentration was adjusted to $2.5 \times 10^{8} / \mathrm{ml}$ with PPP and then divided into 4 equal parts. $\mathrm{CaCl}_{2} / \mathrm{MgCl}_{2}$ in a final concentration of $1 \mathrm{mM}$ was added immediately before platelets activation was initiated with $2.5 \mu \mathrm{M}$ ADP. Platelet activation was stopped by adding an EDTA/PGE1 $(2 \mathrm{mM}$ and $1 \mu \mathrm{g} / \mathrm{ml}$ final concentration, respectively) mixture at 1,3 , and 5 min. No ADP-treated platelets were used as resting platelet control. Platelets were pelleted immediately by centrifugation and lysed in radioimmunoprecipitation assay (RIPA) buffer (ThermoFisher Scientific, Waltham, MA) containing proteinase/phosphatase inhibitor cocktail (ThermoFisher Scientific). Thirty micrograms of total proteins were separated in SDS-PAGE, transferred to a PVDF membrane, and blotted with antibodies as indicated in the Result. Membranes were stripped and re-blotted with an actin antibody as loading control.

\section{Flowcytometry assay of platelet activation}

Platelets in PRP were adjusted to $2.5 \times 10^{8} / \mathrm{ml}$ with PPP and then divided into 8 equal parts. $\mathrm{CaCl}_{2} / \mathrm{MgCl}_{2}$ in a final concentration of $1 \mathrm{mM}$ was added immediately before platelets activation was initiated with $2.5 \mu \mathrm{M}$ ADP. Platelet activation was stopped by adding an EDTA/PGE1 (2 $\mathrm{mM}$ and $1 \mu \mathrm{g} / \mathrm{ml}$ final concentration, respectively) mixture at 1,3 , and $5 \mathrm{~min}$. No ADP-treated platelets were used as resting platelet control. Platelets were then fixed with $2 \%$ paraformaldehyde, and then stained with a FITC conjugated rat anti-mouse p-selectin antibody (BD pharmingen) and analyzed by flowcytometry.

\section{Generation of fusion proteins to determine that TYMP binds to LYN through the SH3 binding domain.}

We previously showed that TYMP binds to Lyn, Fyn and Yes, and this binding may be via the proline-rich N-terminus of TYMP to the SH3 domain in the SFKs. ${ }^{1}$ To further test this hypothesis, the human SH3 domain nucleotides (hLynSH3, amino acids 63-123) was amplified by PCR using primers 5'-ATCGTGGTCGCCCTGTAC-3’ and 5'ATTCAGCTTAGCCACGTAGTTAGAT-3’ and a codon optimized human Lyn encoding plasmid pEGFP-N1-human lyn-GFP (Addgene, plasmid \# 35958) as a template. The hLynSH3 PCR product was cloned into a pCR2.1 TA cloning vector (Invitrogen, Carlsbad CA), transformed into One Shot TOP10 E. coli (Invitrogen), and screened with blue and white selection. The insert orientation was confirmed by PCR sequencing with the M13 forward primer, 5'-GTAAAACGACGGCCAGT-3', and a reverse primer 5'-

ATCGTGGTCGCCCTGTAC-3'. The hLynSH3 domain was further cloned into a mammalian 
expression vector pEBG (Addgene, plasmid \# 22227) with an N-terminal glutathione Stransferase (GST) affinity tag between the restriction sites BamHI and NotI, and a new plasmid pEBG-GST-hLynSH3 was generated.

We had previously constructed a pCDNA6B/his-hTYMP plasmid vector. ${ }^{9}$ pEBG-GSThLynSH3 and pCDNA6B/his-hTYMP plasmids were co-transfected into COS-7 cells using XtremeGENE 9 DNA transfection reagent (Roche, Mannheim Germany). The cells were harvested 36 hours later and lysed in a Pierce ${ }^{\mathrm{TM}}$ IP Lysis Buffer (ThermoFisher Scientific). One milligram of total protein was added to Glutathione MagBeads (GenScript, Piscataway, NJ) and purified by affinity chromatography based on the manufacture's introduction. The GST-hLynSH3 eluates was used for western blot assay to confirm the presence of TYMP.

pEGFP-N1-human Lyn-GFP and pCDNA6B/his-hTYMP plasmids were also cotransfected to the COS-7 cells. TYMP was pulled down using immobilized $\mathrm{Ni}^{+}$on magnetic sepharose beads (GE Healthcare Life Sciences) for His-tagged protein purification. To do this, the cell lysates were adjusted to contain (in mM) 5 imidazole, $200 \mathrm{Na}_{3} \mathrm{PO}_{4}$, and $500 \mathrm{NaCl}$, then adjusted to a $\mathrm{pH}$ of 7.4 before added to the His Mag Sepharose Ni beads. His-hTYMP eluates were used for western blot assay for Lyn.

Statistics. Data were expressed as mean \pm SEM. Results were analyzed by 2-tailed Student's $t$ test or 1-way ANOVA with Bonferroni post-hoc test for multiple comparisons using Graphpad Prism (version 7.03). $P<0.05$ was considered statistically significant.

\section{Literatures cited}

1. Li W, Gigante A, Perez-Perez MJ, et al. Thymidine phosphorylase participates in platelet signaling and promotes thrombosis. Circulation research. 2014;115(12):997-1006.

2. Lopez LC, Akman HO, Garcia-Cazorla A, et al. Unbalanced deoxynucleotide pools cause mitochondrial DNA instability in thymidine phosphorylase-deficient mice. Hum Mol Genet. 2009;18(4):714-722.

3. Li W, McIntyre T, Silverstein R. Ferric chloride-induced murine carotid arterial injury: a model of redox pathology. Redox Biology. 2013;1(1):50-55.

4. Li W, Nieman, M., Sen Gupta, A. Ferric Chloride-induced Murine Thrombosis Models. $J$ Vis Exp. 2016;115:e54479.

5. Pawlowski CL, Li W, Sun M, et al. Platelet microparticle-inspired clot-responsive nanomedicine for targeted fibrinolysis. Biomaterials. 2017;128:94-108.

6. Chen K, Li W, Major J, Rahaman SO, Febbraio M, Silverstein RL. Vav guanine nucleotide exchange factors link hyperlipidemia and a prothrombotic state. Blood. 2011;117(21):5744-5750.

7. Chen K, Febbraio M, Li W, Silverstein RL. A specific CD36-dependent signaling pathway is required for platelet activation by oxidized low-density lipoprotein. Circulation research. 2008;102(12):1512-1519.

8. Ghosh A, Li W, Febbraio M, et al. Platelet CD36 mediates interactions with endothelial cell-derived microparticles and contributes to thrombosis in mice. The Journal of clinical investigation. 2008;118(5):1934-1943.

9. Yue H, Tanaka K, Furukawa T, Karnik SS, Li W. Thymidine phosphorylase inhibits vascular smooth muscle cell proliferation via upregulation of STAT3. Biochimica et biophysica acta. 2012;1823(8):1316-1323. 


\section{Sypplemental figure I}

\section{A: TPI on Apoe-/- mice bleeding}

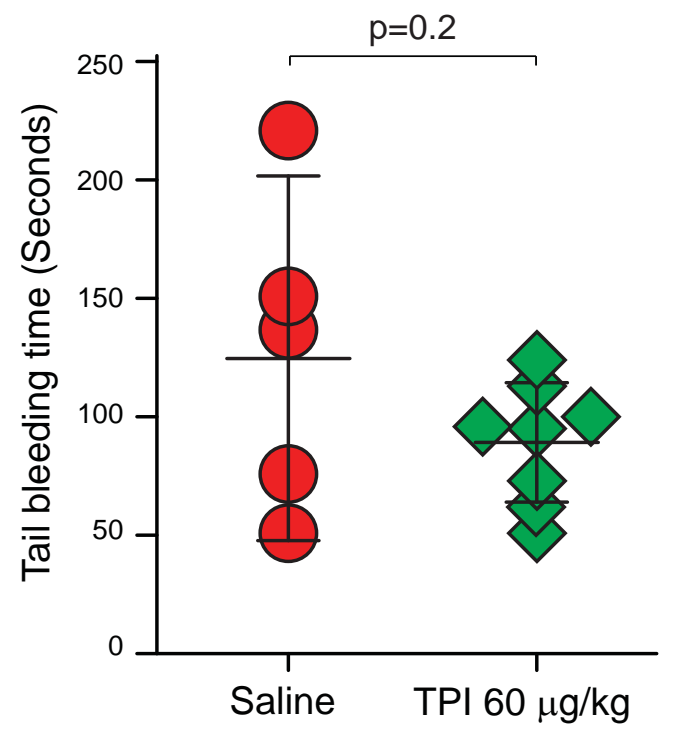

\section{B: TPI on hemoglobin lost during bleeding assay in Apoe ${ }^{-/}$mice}

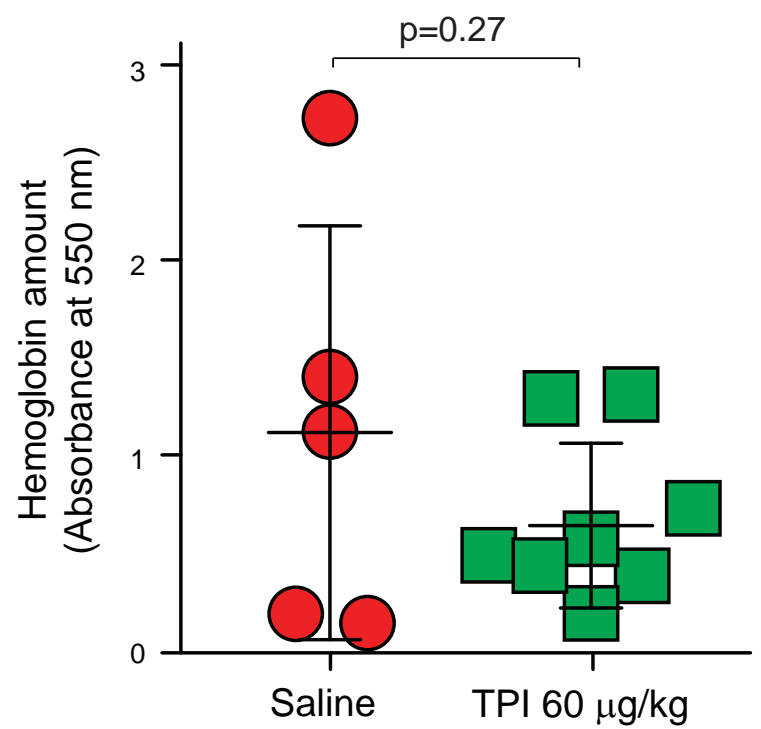

Supplemental figure I. Apoe-/ mice in 8 weeks old were fed with a western diet (TD.88137) and at same time, the mice were gavage fed with TPI at a dose of $60 \mathrm{mg} / \mathrm{kg}$ for 5 weeks. $\boldsymbol{A}$. Tail bleeding time was conducted by cutting $1 \mathrm{~cm}$ length of tail and immersed immediately in $37^{\circ} \mathrm{C}$ saline. B. Red blood cells were collected by centrifuge, lysed in RBC lysis buffer, and hemoglobin amount was evaluated by measuring wavelength absorbance at $550 \mathrm{~nm}$. 


\section{Legends for online supplementary videos}

Supplemental video I: Thrombosis formation in female mice fed with chow.

Supplemental video II: Thrombosis formation in female mice fed with a western diet (TD.88137) for 4 weeks.

Supplemental video III: Thrombosis formation in female mice fed with a western diet (TD.88137) for a total of 4 weeks. From the $4^{\text {th }}$ week, mice received a customized diet TD.190501, which has the same component as TD.88137 with the addition of $10.7 \mathrm{mg} / \mathrm{kg}$ TPI. Mice fed with TD.190501 received approximately $1 \mathrm{mg} / \mathrm{kg} /$ day of TPI.

Supplemental video IV: Thrombosis formation in male WT mice fed with $1 \mathrm{mg} / \mathrm{kg}$ aspirin for 1 week.

Supplemental video V: Thrombosis formation in male WT mice fed with $2.5 \mathrm{mg} / \mathrm{kg}$ clopidogrel for 1 week.

Supplemental video VI: Thrombosis formation in male WT mice fed with $1 \mathrm{mg} / \mathrm{kg}$ TPI for 1 week.

Supplemental video VII: Thrombosis formation was initiated in male WT mouse with 7.5\% $\mathrm{FeCl}_{3}$ treatment for 1 minute. TPI $75 \mu \mathrm{g} / \mathrm{kg}$ and tPA $0.25 \mathrm{mg} / \mathrm{kg}$ in $100 \mu \mathrm{L}$ saline was perfused to the mouse through a jugular vein catheter 5 minutes after vessel injury. Thrombus formation was observed for a total of 30 minutes. 